\title{
Mandatory public reporting of cardiac surgery outcomes: The 2003 to 2014 Massachusetts experience
}

\author{
David M. Shahian, MD, ${ }^{\mathrm{a}, \mathrm{b}}$ David F. Torchiana, MD, ${ }^{\mathrm{b}, \mathrm{c}}$ Daniel T. Engelman, MD, ${ }^{\mathrm{d}}$ \\ Thoralf M. Sundt III, MD, ${ }^{\mathrm{b}, \mathrm{e}}$ Richard S. D’Agostino, MD, ${ }^{\mathrm{f}}$ Ann F. Lovett, MA, RN, ${ }^{\mathrm{b}, \mathrm{g}}$ \\ Matthew J. Cioffi, MS, ${ }^{\text {b,g }}$ James D. Rawn, MD ${ }^{\text {b,h }}$ Vladimir Birjiniuk, MD, ${ }^{i}$ Robert H. Habib, PhD, ${ }^{j}$ and \\ Sharon-Lise T. Normand, $\mathrm{PhD}^{\mathrm{g}, \mathrm{k}}$
}

\section{ABSTRACT}

Objectives: Beginning in 2002, all 14 Massachusetts nonfederal cardiac surgery programs submitted Society of Thoracic Surgeons (STS) National Database data to the Massachusetts Data Analysis Center for mandatory state-based analysis and reporting, and to STS for nationally benchmarked analyses. We sought to determine whether longitudinal prevalences and trends in risk factors and observed and expected mortality differed between Massachusetts and the nation.

Methods: We analyzed 2003 to 2014 expected (STS predicted risk of operative [in-hospital + 30-day] mortality), observed, and risk-standardized isolated coronary artery bypass graft mortality using Massachusetts STS data $(\mathrm{N}=39,400$ cases) and national STS data ( $\mathrm{N}=1,815,234$ cases). Analyses included percentage shares of total Massachusetts coronary artery bypass graft volume and expected mortality rates of 2 hospitals before and after outlier designation.

Results: Massachusetts patients had significantly higher odds of diabetes, peripheral vascular disease, low ejection fraction, and age $\geq 75$ years relative to national data and lower odds of shock (odds ratio, 0.66; 99\% confidence interval, 0.53 0.83 ), emergency (odds ratio, $0.57,99 \%$ confidence interval, $0.52-0.61$ ), reoperation, chronic lung disease, dialysis, obesity, and female sex. STS predicted risk of operative [in-hospital +30 -day] mortality for Massachusetts patients was higher than national rates during 2003 to $2007(P<.001)$ and no different during 2008 to $2014(P=.135)$. Adjusting for STS predicted risk of operative [in-hospital +30 day] mortality, Massachusetts patients had significantly lower odds (odds ratio, $0.79 ; 99 \%$ confidence interval, $0.66-0.96$ ) of 30 -day mortality relative to national data. Outlier programs experienced inconsistent, transient influences on expected mortality and their percentage shares of Massachusetts coronary artery bypass graft cases.

Conclusions: During 12 years of mandatory public reporting, Massachusetts riskstandardized coronary artery bypass graft mortality was consistently and significantly lower than national rates, expected rates were comparable or higher, and evidence for risk aversion was conflicting and inconclusive. (J Thorac Cardiovasc Surg 2019;158:110-24)

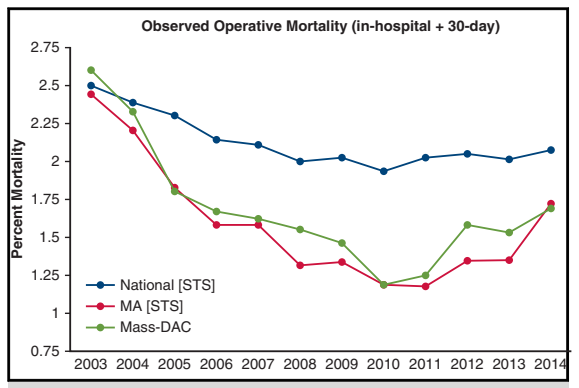

Operative mortality, Society of Thoracic Surgeons (STS) national data (excluding Massachusetts) versus STS data exclusively from Massachusetts and Massachusetts Data Analysis Center (Mass-DAC)

\section{Central Message}

From 2003-2014, risk-adjusted CABG outcomes in Massachusetts, a public reporting state, were consistently superior to STS national results; evidence for risk aversion was conflicting and inconclusive.

\section{Perspective}

During 12 years of mandatory public reporting (2003-2014), Massachusetts risk-adjusted CABG mortality was consistently lower than national rates, expected mortality was comparable or higher, and evidence for risk aversion was inconclusive. These nationally benchmarked results support continued study of public reporting as a mechanism to educate patients and potentially to improve health care outcomes.

See Commentary on page 125 .

\footnotetext{
From the ${ }^{\mathrm{a}}$ Department of Surgery and Center for Quality and Safety, and ${ }^{\mathrm{e}}$ Division of Cardiac Surgery, Massachusetts General Hospital, Boston, Mass; ${ }^{\mathrm{b}}$ Harvard Medical School, Boston, Mass; ${ }^{\mathrm{C}}$ Partners HealthCare, Boston, Mass; ${ }^{\mathrm{d}}$ Division of Cardiac Surgery, Baystate Medical Center, University of Massachusetts-Baystate, Springfield, Mass; ${ }^{\mathrm{f}}$ Department of Thoracic and Cardiovascular Surgery, Lahey Health System, Burlington, Mass; ' Department of Health Care Policy, Harvard Medical School, Boston, Mass; ${ }^{\mathrm{h}}$ Division of Cardiac Surgery, Brigham and Women's Hospital, Boston, Mass; ${ }^{i}$ Division of Cardiothoracic Surgery, Mt Auburn Hospital, Cambridge, Mass; ${ }^{j}$ The Society of Thoracic Surgeons Research Center; and $^{\mathrm{K}}$ T.H. Chan School of Public Health, Harvard University, Boston, Mass.
}

Read at the 98th Annual Meeting of The American Association for Thoracic Surgery, San Diego, California, April 28-May 1, 2018.

Received for publication Sept 3, 2018; revisions received Nov 30, 2018; accepted for publication Dec 4, 2018; available ahead of print Feb 14, 2019.

Address for reprints: David M. Shahian, MD, Department of Surgery, Massachusetts General Hospital, 55 Fruit St, Boston, MA 02114 (E-mail: dshahian@partners. org).

$0022-5223 / \$ 36.00$

Copyright $(\subset 2019$ by The American Association for Thoracic Surgery https://doi.org/10.1016/j.jtcvs.2018.12.072 


\section{Abbreviations and Acronyms \\ ACSD = Society of Thoracic Surgeons Adult Cardiac Surgery Database \\ $\mathrm{CABG}=$ coronary artery bypass grafting \\ $\mathrm{CY}=$ calendar year \\ DPH $=$ Department of Public Health \\ $\mathrm{EF} \quad=$ ejection fraction \\ $\mathrm{FY} \quad=$ fiscal year \\ Mass-DAC $=$ Massachusetts Data Analysis Center \\ $\mathrm{O} / \mathrm{E} \quad=$ observed to expected ratio \\ PCI = percutaneous coronary intervention \\ PVD = peripheral vascular disease \\ STS-PROM $=$ Society of Thoracic Surgeons predicted risk of mortality}

\section{fif Scanning this $Q R$ code will take you to the article title page to access supplementary informa- tion. To view the AATS Annual Meeting Webcast, see the URL next to the webcast thumbnail.}

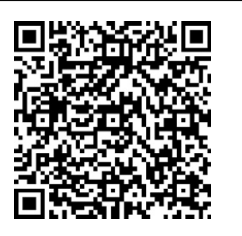

Public reporting of hospital-specific outcomes by government and commercial organizations remains highly controversial. Proponents cite the need for transparency and accountability, the ethical obligation to facilitate informed decision making by consumers and referring physicians, and the ability of report cards to stimulate performance improvement. Detractors are concerned about the accuracy and effectiveness of report cards and their unintended consequences such as gaming, risk aversion, and reduced access to care. ${ }^{1-10}$

The Massachusetts cardiac surgery public reporting program provides a unique natural laboratory in which to study these issues. State legislation mandates the use of the Society of Thoracic Surgeons (STS) Adult Cardiac Surgery Database (ACSD) by all cardiac surgery programs, which ensures a highly representative, audited, and risk-adjusted national comparator for Massachusetts, using identical data specifications.

Beginning January 2002, Massachusetts Department of Public Health (DPH) required collection of clinical and vital status data from all 14 nonfederal Massachusetts cardiac surgery programs, stipulating participation in the STS ACSD $^{11,12}$ and parallel submission of fully identified data to the Massachusetts Data Analysis Center (Mass-DAC). Reports of hospital outcomes for isolated coronary artery bypass grafting (CABG) were published for 2002 to 2014 procedures, and surgeon outcomes for 2002 to 2010 procedures. $^{13}$

Because of common STS ACSD data platforms, crosssectional and longitudinal analyses of cardiac surgical practice in Massachusetts versus STS national data are facilitated. We leverage this to compare Massachusetts and STS isolated CABG volumes; expected, observed, and riskstandardized outcomes; and risk factor prevalences. The value of peer coding adjudication in Massachusetts and the consequences of outlier designation were also studied.

\section{METHODS \\ Study Populations}

We excluded 2002 data due to inaugural year coding issues, similar to early New York reports. ${ }^{14,15}$

We analyzed 3 populations of adults aged 18 years or older undergoing isolated CABG between January 1, 2003, and December 31, 2014: isolated CABG cases submitted to STS from Massachusetts hospitals (MA [STS] cohort, $\mathrm{n}=39,400)$, isolated CABG procedures submitted to STS from US states, excluding Massachusetts (national [STS] cohort, $\mathrm{n}=$ $1,815,234)$, and isolated CABG cases in all nonfederal Massachusetts hospitals, submitted to Mass-DAC $(n=40,655)$ for the Massachusetts public reporting program. The additional Mass-DAC cases compared with cases submitted to STS reflects slight differences in isolated CABG case inclusion criteria between the 2 sources.

\section{Data Sources}

We used information publicly reported on the Massachusetts $\mathrm{DPH}^{13}$ and STS websites, ${ }^{16}$ previously published Mass-DAC reports, and additional data provided by these organizations.

\section{Patient and Hospital Outcomes}

Mass-DAC reports observed, expected, and risk-standardized 30-day all-cause mortality. STS reports observed and expected operative mortality, which includes all deaths during the index hospitalization, regardless of timing, and all deaths within 30 days regardless of location. In addition to these standard reports, we extracted STS 30-day observed mortality and Mass-DAC operative mortality from original data sources.

\section{Data Collection and Quality Assurance}

STS cohort. STS ACSD data specifications, cleaning, and quality assurance processes are published elsewhere. ${ }^{11,12,17}$ Annual external audits of $10 \%$ of participating programs demonstrate $95 \%$ to $97 \%$ overall agreement rates. During the study period, multiple STS ACSD versions (2.35-2.81) were used depending on year.

Data submitted to STS were missing $<1 \%$ for most variables, presumably because Massachusetts data managers were required to have complete data for their contemporaneous Mass-DAC submissions. Patients with missing or unknown operative mortality status were assumed alive, consistent with STS coding practice during the study period.

Mass-DAC cohort. Mass-DAC data collection, cleaning, and quality assurance processes are published elsewhere. ${ }^{13,18}$ Mass-DAC reports information assembled from several linked data sources. Patient-specific risk factor and outcome data are collected by trained hospital personnel using standard STS ACSD data submission forms. ${ }^{17,18}$ External administrative data resources and medical record review are used to validate submitted data and to ascertain or verify 30-day vital status (Table E1). Missing data were extremely rare.

Before analyses, Mass-DAC charts coded for selected risk factors (routinely: shock, emergent or emergent/salvage status, myocardial 
infarction $<24$ hours, and, beginning 2012, peripheral vascular disease [PVD]; periodically, low ejection fraction [EF], moderate/severe chronic lung disease, or dialysis) were adjudicated by surgeons and data managers from all 14 programs, as previously described for Mass-DAC percutaneous coronary intervention (PCI) public reporting. ${ }^{19}$

Using published procedure classification criteria ${ }^{13,18}$ and clinical review of medical records and operative notes, all procedures coded "CABG + other" were also adjudicated, based on the magnitude and incremental risk of the "other" procedure, to confirm they were not isolated CABG cases that were intentionally or inadvertently coded as combined procedures (that are not publicly reported).

\section{Expected Mortality and Outlier Determination}

STS cohort. For operational feedback reports, STS recalibrates its risk models to achieve a ratio of observed to expected mortality $(\mathrm{O} / \mathrm{E})$ of 1 and periodically estimates completely new models. ${ }^{20-24}$ Depending on the specific procedure and outcome measure, outlier determination is typically based on $95 \%$ or $98 \%$ Bayesian credible intervals. ${ }^{25}$ For this study, to facilitate longitudinal analyses of expected mortality trends, the same 2008 STS CABG risk mode ${ }^{20}$ was applied to patients from each year. Mass-DAC cohort. Mass-DAC develops its own 30-day mortality risk models based solely on data from Massachusetts programs and reestimates these annually. ${ }^{13,18}$ Because of frequent re-estimation and only 14 programs, annual Massachusetts $\mathrm{O} / \mathrm{E}$ ratios are typically close to unity.

Fully Bayesian hierarchical logistic (surgery years 2002-2009) and Poisson (surgical procedures beginning in 2010) regression models are estimated that include hospital-specific random intercepts.

Hospitals were categorized as outliers if their standardized mortality incidence rate $95 \%$ credible interval excluded the statewide average, or if their observed mortality rate was statistically different from that predicted by all other hospitals (ie, with the problematic hospital's data excluded from risk model development).

The Massachusetts Cardiac Care Outlier Committee (composed of surgeons from the Massachusetts STS) reviewed Mass-DAC annual results before final release, including clinical information from statistical outliers, to determine whether there were systemic versus unique case mix issues to explain low performance.

\section{Statistical Analyses}

We compared longitudinal trends in Massachusetts isolated CABG volume with trends from STS (national) and from New York, another public reporting state.

Expected and adjusted mortality rate analyses comparing Massachusetts and national [STS] cohorts used MA [STS] data (similar to MassDAC data) and STS predicted risk of operative mortality (PROM). Risk factor prevalence comparisons primarily used peer-adjudicated MassDAC data, supplemented by MA [STS] data.

We analyzed annual observed operative and 30-day mortality rates for all 3 study cohorts; expected operative mortality rates and O/E ratios for national [STS] and MA [STS] cohorts, using STS risk models; and expected 30-day mortality for the Mass-DAC cohort.

To statistically compare national [STS] and Massachusetts risk factor prevalences, surgical outcomes, and their corresponding longitudinal changes, we estimated separate logistic regression models for 15 selected risk factors and for observed operative and 30-day mortality. We linked the log-odds of each end point (ie, risk factor or mortality) to categorical variables indicating Massachusetts (Mass-DAC data source for risk factors, MA [STS] data source for mortality) versus national [STS] data, year of surgery (year 0 [2003] to year 11 [2014]), and an interaction of Massachusetts indicator and year; for mortality, these regressions were also estimated with adjustment for STS PROM, a summary risk score based on patient factors. Significant odds ratios (ORs) for interaction terms imply that annual rates of change in mortality or risk factor odds differed between
Massachusetts and national [STS] data; when interaction terms are nonsignificant, the MA indicator represents the overall OR between Massachusetts and national [STS], and the year indicator is the overall rate of change. We noted if annual trends were increasing or decreasing in both cohorts, or directionally opposite. To minimize family-wise error rate, we used conservative $99 \%$ confidence intervals.

We explored hospital-specific percentage shares of Massachusetts CABG volumes between 2003 and 2014, changes in the share of CABG cases at 2 outlier hospitals, and expected mortality rate trends of outlier hospitals compared with the volume weighted average expected mortality (Mass-DAC models) for all Massachusetts hospitals.

Mass-DAC used hospital-aggregated, de-identified data. Raw data and procedures associated with assessing hospital quality were reviewed by the Harvard Medical School Institutional Review Board. STS data were likewise de-identified, and STS data collection and analysis procedures were reviewed by the Duke Institutional Review Board.

\section{RESULTS \\ CABG Volumes}

Massachusetts isolated CABG admissions declined $33.5 \%$ from $2002(\mathrm{n}=4603)$ to $2014(\mathrm{n}=3063)$, less than the $56.1 \%$ decrease in comparable STS procedures/ program nationally, the $52.7 \%$ decrease among 388 sites participating continuously in the STS ACSD from 2002 to 2014, and the 50.7\% decrease in New York (Table E2).

\section{Mass-DAC Verification of Case Completeness and Deaths}

Between 2004 and 2014, Mass-DAC verification of case completeness and vital status resulted in 0 to 2 (mean, 0.9) additional isolated $\mathrm{CABG}$ procedures $(0.03 \%$ of all cases) and 0 to 5 (mean, 2$)$ net 30 -day mortalities $(0.06 \%$ of all cases) added annually to data submitted by hospitals.

\section{Mass-DAC Adjudication}

From 2002 to 2014, 541 to 781 total CABG cases (mean, $636.8)$ were reviewed annually for various indications, including 273 to 724 risk variable (mean, 445.8) audits. Excluding 2002, 38-138 (mean, 82.7) risk variables annually had coding changes.

Detailed annual adjudication data are available from 2007 to 2014 (Table E3) for high-risk variables and to substantiate $\mathrm{CABG}+$ other procedure designation. Compared with the $9.8 \%$ decline in isolated $\mathrm{CABG}$ volume during this period, cases submitted with shock or emergent/emergent-salvage status declined substantially more (eg, shock, 67\% decrease; emergent/emergent-salvage, $41 \%$ decrease), as did their submission rates as percentages of isolated $\mathrm{CABG}$ cases and their rates of coding changes.

Between 2007 and 2014, 70 to 174 (mean, 122) procedures annually were coded by hospitals as CABG + other. Both the number (149 to 98 ) of submitted CABG + other cases and the number changed to isolated CABG ( 93 to 55) decreased between 2007-2014; overall, between $33.1 \%$ and $65.4 \%$ $\mathrm{CABG}+$ other cases were reclassified isolated CABG. 
TABLE 1. Risk factor prevalences, Massachusetts versus national [STS ]

\begin{tabular}{|c|c|c|c|c|c|c|c|c|c|c|c|c|c|c|}
\hline \multirow[b]{2}{*}{ Year } & \multicolumn{2}{|c|}{ Mean age (y) } & \multicolumn{2}{|c|}{ Age 65- 74 y (\%) } & \multicolumn{2}{|c|}{ Age $\geq 75$ y $(\%)$} & \multicolumn{2}{|c|}{ Female (\%) } & \multicolumn{2}{|c|}{ EF 0.30- 0.39 (\%) } & \multicolumn{2}{|c|}{$\mathbf{E F}<0.30(\%)$} & \multicolumn{2}{|c|}{ CVD (\%) } \\
\hline & STS & Mass-DAC & STS & Mass-DAC & STS & Mass-DAC & STS & Mass-DAC & STS & Mass-DAC & STS & Mass-DAC & STS & Mass-DAC \\
\hline 2003 & 65.0 & 66.7 & 31.6 & 32.1 & 21.8 & 26.8 & 27.9 & 26.5 & 10.7 & 12.4 & 6.4 & 7.7 & 13.5 & 14.0 \\
\hline 2004 & 65.1 & 66.9 & 31.5 & 32.2 & 22.2 & 27.8 & 27.9 & 25.5 & 10.4 & 11.0 & 6.3 & 8.4 & 14.0 & 14.8 \\
\hline 2005 & 65.1 & 66.4 & 31.3 & 31.2 & 22.0 & 26.0 & 27.2 & 23.6 & 10.5 & 10.9 & 6.4 & 8.1 & 13.7 & 14.1 \\
\hline 2006 & 65.0 & 66.3 & 31.5 & 31.3 & 21.5 & 25.6 & 27.3 & 24.4 & 10.1 & 9.9 & 6.3 & 6.3 & 13.7 & 13.7 \\
\hline 2007 & 64.9 & 66.0 & 31.3 & 30.7 & 21.0 & 25.1 & 27.1 & 24.3 & 10.1 & 10.9 & 6.3 & 6.8 & 13.7 & 14.0 \\
\hline 2008 & 64.8 & 66.0 & 31.8 & 31.8 & 20.4 & 24.5 & 27.3 & 22.4 & 9.6 & 10.1 & 6.2 & 5.5 & 14.2 & 12.9 \\
\hline 2009 & 64.8 & 66.1 & 32.4 & 33.0 & 20.0 & 23.8 & 26.9 & 22.5 & 9.4 & 9.1 & 6.2 & 6.4 & 14.3 & 14.8 \\
\hline 2010 & 64.8 & 65.8 & 32.7 & 32.1 & 19.9 & 23.0 & 26.3 & 22.9 & 9.3 & 9.4 & 6.0 & 6.2 & 14.5 & 13.3 \\
\hline 2011 & 64.9 & 66.2 & 32.9 & 32.4 & 19.7 & 23.9 & 26.4 & 22.4 & 9.3 & 9.9 & 6.1 & 5.8 & 14.1 & 15.4 \\
\hline 2012 & 64.8 & 66.1 & 33.8 & 35.1 & 19.2 & 22.1 & 26.1 & 22.2 & 9.5 & 9.1 & 6.2 & 5.5 & 14.1 & 14.2 \\
\hline 2013 & 65.0 & 66.3 & 34.6 & 32.7 & 19.4 & 24.5 & 25.7 & 22.4 & 9.4 & 8.8 & 6.3 & 5.8 & 14.2 & 13.9 \\
\hline 2014 & 64.9 & 66.5 & 34.6 & 36.3 & 18.9 & 23.5 & 25.1 & 22.0 & 9.4 & 8.3 & 6.4 & 5.9 & 16.5 & 17.2 \\
\hline
\end{tabular}

\begin{tabular}{|c|c|c|c|c|c|c|c|c|c|c|c|c|c|c|c|}
\hline & \multicolumn{2}{|c|}{ Dialysis (\%) } & \multicolumn{3}{|c|}{ Morbid obesity (\%) } & \multicolumn{3}{|c|}{ Reoperation (\%) } & \multicolumn{3}{|c|}{ Moderate/severe CLD (\%) } & \multicolumn{2}{|c|}{ Diabetes $(\%)$} & \multicolumn{2}{|c|}{ Insulin dependent $(\%)$} \\
\hline & $\overline{\text { STS }}$ & Mass-DAC & \multicolumn{3}{|c|}{ Mass-DAC } & \multirow[t]{2}{*}{$\overline{\text { STS }}$} & \multicolumn{2}{|c|}{ Mass-DAC } & \multicolumn{2}{|c|}{ STS } & Mass-DAC & $\overline{\text { STS M }}$ & $\overline{\text { Mass-DAC }}$ & \multirow{2}{*}{$\begin{array}{c}\text { STS } \\
10.2\end{array}$} & Mass-DAC \\
\hline 2003 & 1.5 & 1.3 & 14.3 & & & & & & 9 & & 6.0 & 35.8 & 38.1 & & 12.2 \\
\hline 2004 & 1.6 & 1.4 & 14.3 & & & 5.3 & & & 9 & & 5.6 & 36.2 & 37.0 & 10.5 & 10.6 \\
\hline 2005 & 1.7 & 1.2 & 14.9 & & & 4.8 & & & 9 & & 5.5 & 36.8 & 39.3 & 11.2 & 11.7 \\
\hline 2006 & 1.8 & 1.8 & 15.3 & & & 4.6 & & & 9 & & 5.9 & 37.6 & 40.0 & 11.4 & 12.5 \\
\hline 2007 & 1.9 & 1.9 & 15.8 & & & 4.4 & & & 9 & & 5.8 & 39.1 & 41.8 & 12.1 & 14.4 \\
\hline 2008 & 2.4 & 2.1 & 16.3 & & & 4.1 & & & 9 & & 6.3 & 39.7 & 37.3 & 12.9 & 11.8 \\
\hline 2009 & 2.5 & 2.4 & 16.7 & & & 3.9 & & & 10 & & 5.1 & 40.5 & 39.3 & 13.6 & 12.9 \\
\hline 2010 & 2.6 & 2.3 & 16.8 & & & 3.8 & & & 10 & & 5.8 & 41.4 & 39.7 & 14.1 & 14.6 \\
\hline 2011 & 2.8 & 2.0 & 17.1 & & & 3.6 & & & 10 & & 5.8 & 43.1 & 41.5 & 15.0 & 15.1 \\
\hline 2012 & 2.8 & 1.6 & 17.4 & & & 3.4 & & & 10 & & 4.8 & 44.9 & 43.1 & 15.9 & 15.9 \\
\hline 2013 & 2.8 & 2.2 & 17.3 & & & 3.1 & & & 10 & & 4.7 & 45.7 & 44.5 & 16.9 & 17.4 \\
\hline \multirow[t]{3}{*}{2014} & 3.0 & 2.3 & 17.7 & & & 2.9 & & & 10 & & 5.6 & 47.3 & 43.8 & 17.5 & 17.6 \\
\hline & \multicolumn{4}{|c|}{ Cardiogenic shock $(\%)$} & \multicolumn{5}{|c|}{ Emergent \pm salvage $(\%)$} & \multicolumn{3}{|c|}{ MI $<24$ h (\%) } & \multicolumn{3}{|c|}{ PVD $(\%)$} \\
\hline & $\overline{\text { STS }}$ & Mass-DAC & & $\overline{\text { [STS] }}$ & $\overline{\text { STS }}$ & Mass & DAC & $\overline{\mathrm{MA}}$ & $\overline{\text { STS] }}$ & $\overline{\text { STS }}$ & Mass-DAC & MA [STS] & $\overline{\mathrm{STS}}$ & Mass-DAC & MA [STS] \\
\hline 2003 & 1.9 & 1.6 & & 2.1 & 4.6 & & & & & 3.9 & 3.1 & 3.1 & 15.7 & 17.4 & 17.4 \\
\hline 2004 & 1.9 & 1.1 & & 2.2 & 4.8 & & & & & 4.2 & 3.8 & 4.2 & 15.4 & 17.7 & 17.8 \\
\hline 2005 & 2.0 & 1.0 & & 1.9 & 5.0 & & & & & 4.5 & 2.9 & 3.6 & 15.5 & 17.5 & 17.3 \\
\hline 2006 & 2.0 & 0.8 & & 1.7 & 5.0 & & & & & 4.6 & 3.7 & 4.2 & 15.3 & 17.7 & 17.7 \\
\hline 2007 & 2.0 & 0.9 & & 1.6 & 4.9 & & & & & 4.7 & 3.1 & 4.1 & 15.1 & 17.1 & 17.1 \\
\hline 2008 & 2.0 & 0.7 & & 1.4 & 4.7 & & & & & 4.4 & 3.3 & 3.7 & 14.8 & 14.1 & 14.0 \\
\hline 2009 & 1.9 & 0.6 & & 1.1 & 4.6 & & & & & 4.3 & 2.4 & 2.7 & 15.0 & 15.3 & 15.2 \\
\hline 2010 & 2.0 & 0.5 & & 1.0 & 4.5 & & & & & 4.3 & 2.6 & 2.8 & 15.1 & 15.5 & 15.5 \\
\hline 2011 & 2.0 & 0.4 & & 0.6 & 4.7 & & 6 & & & 4.2 & 2.7 & 2.8 & 14.6 & 15.5 & 15.8 \\
\hline 2012 & 2.0 & 0.7 & & .6 & 5.0 & & & & & 4.0 & 2.4 & 2.3 & 14.2 & 11.8 & 14.1 \\
\hline 2013 & 1.8 & 0.8 & & 0.9 & 4.8 & & & & & 3.9 & 2.8 & 2.4 & 14.1 & 12.6 & 14.1 \\
\hline 2014 & 2.0 & 0.6 & & 0.8 & 4.8 & & & & & 3.6 & 2.5 & 2.2 & 14.4 & 12.5 & 14.5 \\
\hline
\end{tabular}

For 4 risk factors that underwent peer-adjudication in Massachusetts, Table 1 includes prevalences of those factors in data submitted directly from Massachusetts programs to the Society of Thoracic Surgeons (STS) national database (MA [STS]), as well as the comparable prevalences in Massachusetts Data Analysis Center (MassDAC) data following peer-adjudication. $E F$, Ejection fraction; $C V D$, cerebrovascular disease; STS, Society of Thoracic Surgeons; $D A C$, Data Analysis Center; $C L D$, chronic lung disease; $M I$, myocardial infarction; $P V D$, peripheral vascular disease. 
MA relative to National STS

MA<STS MA $>$ STS

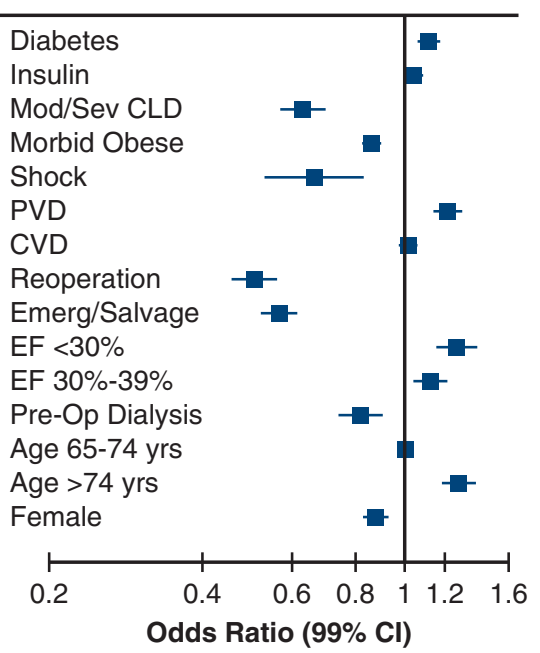

\section{A}

FIGURE 1. Multivariable logistic regression analysis of selected risk factor odds, 2003 to 2014. To statistically compare national [STS] and Massachusett risk factor prevalences and their longitudinal changes, we estimated separate logistic regression models for 15 selected risk factors. We linked the log-odds of each risk factor to categorical variables indicating Massachusetts Data Analysis Center (Mass-DAC) versus national STS data (excluding MA patients), year of surgery (year 0 [2003] to year 11 [2014]), and an interaction of Mass-DAC indicator and year. Significant odds ratios for interaction terms imply that annual rates of change in risk factor odds differed between Massachusetts and national [STS] data; when interaction terms are non-significant, the MA indicator represents the overall odds ratio between Massachusetts and national [STS], and the year indicator is the overall rate of change. We noted if annual trends were increasing or decreasing in both cohorts, or directionally opposite. Odds ratios with $99 \%$ confidence intervals (CI) are summarized for the 3 model co-variables: A, Massachusetts $(M A)($ Yes/No $)=$ MA relative to national STS. B, Year $=$ Annual change $(2003=0$ increasing to $2014=11)$. C, MA $\times$ Year (interaction term) $=$ Annual change in MA relative to annual change in national STS. STS, Society of Thoracic Surgeons; Mod/Sev CLD, Moderate or severe chronic lung disease; $P V D$, peripheral vascular disease; $C V D$, cerebrovascular disease; $E F$, ejection fraction; Pre-op, preoperative.

\section{Mass-DAC Versus STS Risk Factor Prevalence}

Massachusetts risk factor prevalences (ie, Mass-DAC and MA [STS]) are compared with national [STS] prevalences between 2003 and 2014 in Table 1 and Figure E1 through E5. Mass-DAC and MA [STS] rates closely agreed for most, but not all (eg, several peer-adjudicated variables) risk factors.

Regression analysis results of selected risk factors are summarized in Figure 1 and Table E4. Relative to national [STS] patients, adjudicated Mass-DAC data showed significantly lower odds of cardiogenic shock, reoperation, emergency/emergency-salvage, chronic lung disease, dialysis, morbid obesity, and female sex; and significantly greater odds of diabetes, PVD, low EF, age $\geq 75$ years (Figure 1, B). Annual rates of change in risk factor odds in Massachusetts relative to national [STS] data were not statistically different for 8 of 15 risk factors studied. Odds of cardiogenic shock decreased significantly in Massachusetts relative to national [STS] rates, which were slightly increasing during the study period [Figure 1, $C]$ ). Odds of diabetes increased at a slightly slower rate in Massachusetts than nationally, whereas odds of PVD, EF 0.30 to 0.39 and $\mathrm{EF}<0.30$, and female sex fell faster in Massachusetts.

\section{Operative and 30-Day Mortality}

Massachusetts observed operative (Figure 2, A) and 30day (Figure E6) mortality rates were no different than national [STS] rates in 2003, then became significantly and consistently lower than STS national rates, although they increased after 2011. For several annual reports of operative and 30-day mortality, Mass-DAC observed mortality rates were slightly higher than MA [STS] rates, probably reflecting enhanced vital status verification.

Using the STS isolated CABG risk model, MA [STS] PROM rates were higher than national [STS] rates from 2003 to $2007(P<.001)$ but declining, compared with relatively flat national [STS] expected rates; from 2008-2014, MA [STS] and national [STS] PROM rates were similar $(P=.135)$ and stable (Figure 2, $B)$. Using STS data and risk models, MA [STS] O/E for operative mortality generally ranged from 0.6 to 0.8 (Figure E7). 


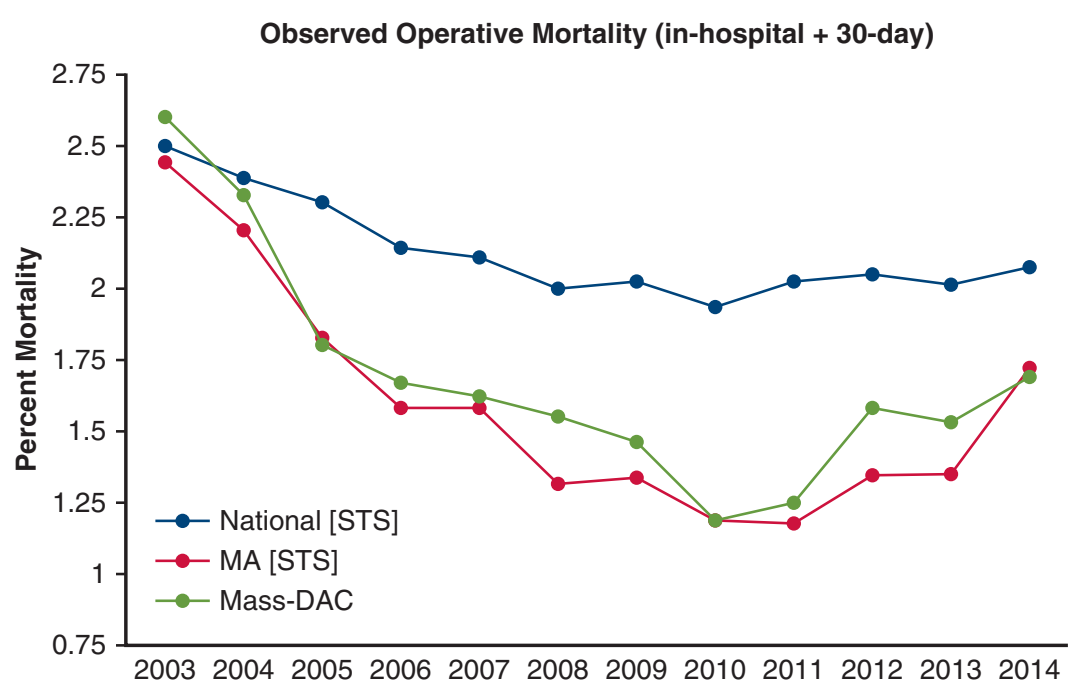

A

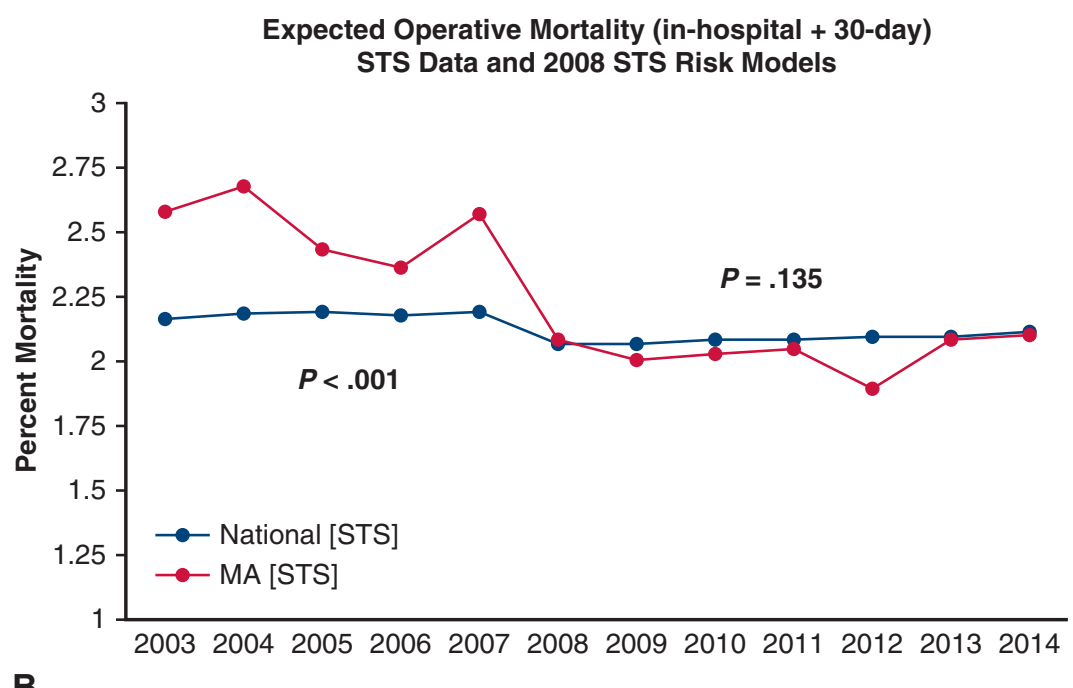

FIGURE 2. Expected and observed mortality rates. A, Observed operative mortality for the Society of Thoracic Surgeons (STS) national cohort (excluding Massachusetts (MA) patients), MA patient data submitted by hospitals directly to STS (MA [STS]), and Massachusetts data adjudicated and verified by the Massachusetts Data Analysis Center (Mass-DAC), which captured a few more deaths in certain years. B, Expected operative mortality rates (inhospital + 30-day) for the national [STS] cohort and MA [STS] cohorts, based on STS data and STS 2008 risk models.

Because Mass-DAC risk models for Massachusetts public reporting were derived only from Massachusetts programs and re-estimated annually, observed and expected 30-day mortality rates tracked very closely (Figure E8).

In regression analyses incorporating STS PROM, the MA [STS] CABG cohort had significantly lower adjusted odds of operative (OR, 0.82; 99\% confidence interval, 0.690.98 ) and 30-day (OR, 0.79; 99\% confidence interval, 0.66-0.96) mortality relative to the national [STS] cohort (Figure 3), with no significant difference in the annual change in MA [STS] mortality odds relative to the annual change in national $[\mathrm{STS}]$ cohort odds $(\mathrm{MA} \times$ Year interaction term).

\section{Surgeon-Level Reports}

Massachusetts provided surgeon-level reports for procedures performed between 2002 and 2010 (last report February 2012 based on fiscal year [FY] 2008-2010 data). Two high-mortality surgeon outliers were identified in calendar year (CY) 2002-2004 report (published 2006), 3 in the CY2003-CY2005 report (published in 2007), and 2 in the FY2003-FY2006 report (published in February 2008). Because of overlapping 3-year time windows, the same 

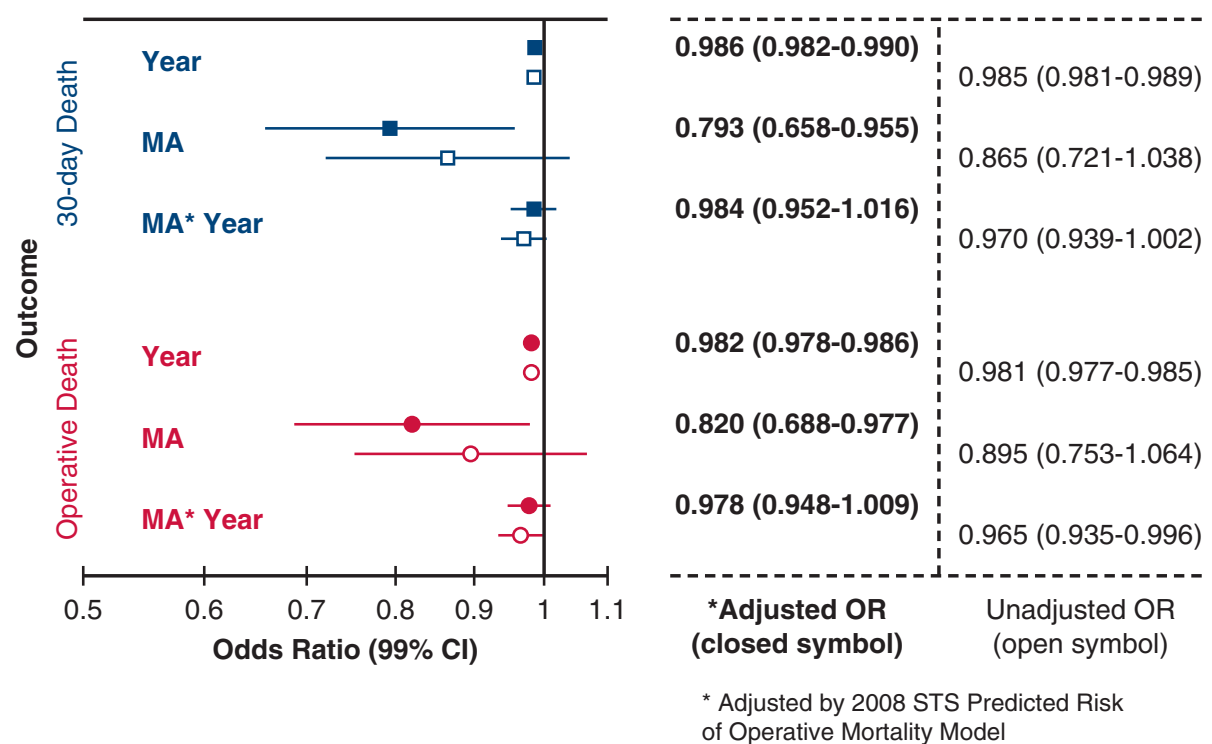

FIGURE 3. Operative and 30-day mortality odds and relative change in odds, Massachusetts STS (MA [STS]) data versus national STS data (excluding MA patients). To statistically compare national and Massachusetts surgical outcomes and their longitudinal changes, we estimated logistic regression models for observed operative and 30-day mortality. We linked the log-odds of each end point to categorical variables indicating MA [STS] versus national [STS] data, year of surgery (Year: 0 [2003] to 11 [2014]), and an interaction of MA indicator and year. These regressions were also estimated with adjustment for STS predicted risk of mortality, a summary risk score based on patient factors. Significant odds ratios for interaction terms imply that annual rates of change in mortality differed between Massachusetts and national data; when interaction terms are nonsignificant, the MA indicator represents the overall odds ratio between Massachusetts and national data, and the year indicator is the overall rate of change. Multivariable logistic regression analysis results shown for operative (red) and 30-day (blue) mortality outcomes without (unadjusted, open symbols) and with (adjusted, closed symbols) risk-adjustment using 2008 STS predicted risk of operative mortality model. Covariates: MA (Yes/No) = MA relative to national STS; Year $=$ annual change $(2003=$ 0 increasing to $2014=11$ ); MA $\times$ Year (interaction term) = annual change in MA mortality odds relative to annual change in national STS mortality odds. OR, Odds ratio; $99 \%$ CI, 99\% confidence interval.

outliers were identified in several reports. There were only 3 unique outlier surgeons, all at outlier hospitals.

\section{Consequences of Outlier Designation}

Subsequent expected mortality rates. Two Massachusetts hospitals were transiently designated as 30-day high mortality outliers-Hospital A in 2005 and 2007 reports (2003 and 2005 procedures); and Hospital B in the 2006 report (2004 procedures). Before outlier designation, both hospitals had higher expected mortality rates than the volume weighted state average (Figure 4).

Massachusetts DPH temporarily closed Hospital A's program after its first outlier designation, leading to extensive structural, personnel, and leadership changes. Although again an outlier 2 years later, their results were substantially improving. Hospital A's expected mortality decreased after its initial outlier designation, but by 2010 its expected mortality rate had returned to the state average, which it tracked closely thereafter (Figure 4).

Hospital B's expected mortality increased slightly following outlier designation, then converged toward and tracked the state mean from 2010 to 2011 onward.

\section{Share of Massachusetts CABG Cases}

Following initial outlier designation (CY2003 report, published in October 2005) and temporary closure, Hospital A's share of all Massachusetts CABG cases dropped from $6.5 \%$ (2005) to $4.9 \%$ (2006). With implementation of numerous changes recommended by a state-mandated panel of experts, outcomes improved and their percentage share of Massachusetts CABG cases rebounded to $7.1 \%$ in 2007 , with steady increases thereafter despite their second identification as an outlier (October 2007, based on CY2005 outcomes) (Figure 5).

Hospital B experienced growth in its share of Massachusetts CABG volume from $4.4 \%$ to $4.7 \%$ the year following its outlier designation (CY2004 report, published October 2006); this percentage then stabilized for 4 years and subsequently increased.

Overall, both Hospitals A and B, despite their transient outlier status, experienced substantial increases in their percentage shares of Massachusetts CABG volume from 2003 to 2014 (18.7\% and $37.1 \%$, respectively) (Figure 6). 


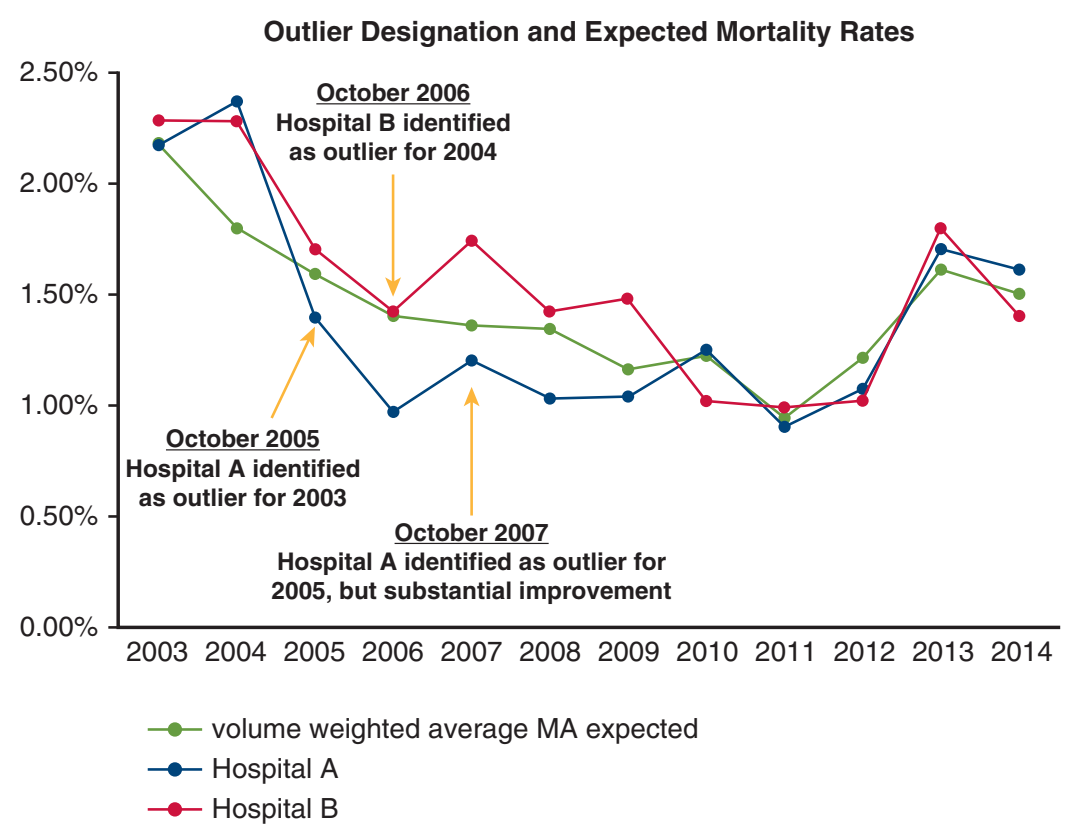

FIGURE 4. Outlier designation and expected mortality rates. Before outlier designation, both hospitals had higher expected mortality rates than the volume weighted state average. As a result of its outlier designation, Hospital A temporarily suspended its cardiac program and made extensive, state-recommended changes. Although again an outlier 2 years later, their results were substantially improving. Hospital A's expected mortality decreased after its initial outlier designation; by 2010, its expected mortality rate had returned to the state average, which it tracked closely thereafter. Hospital B's expected mortality increased slightly following outlier designation, then converged towards and tracked the state mean from 2010-2011 onward.

\section{DISCUSSION}

Massachusetts observed mortality was significantly and consistently less than the STS PROM for its case-mix
$(\mathrm{O} / \mathrm{E}<1)$, and adjusted mortality odds were about $20 \%$ lower than national STS results. These findings could be associated with public reporting, especially since

Change in Percentage Share of Massachusetts CABG Cases For Two Outlier Hospitals

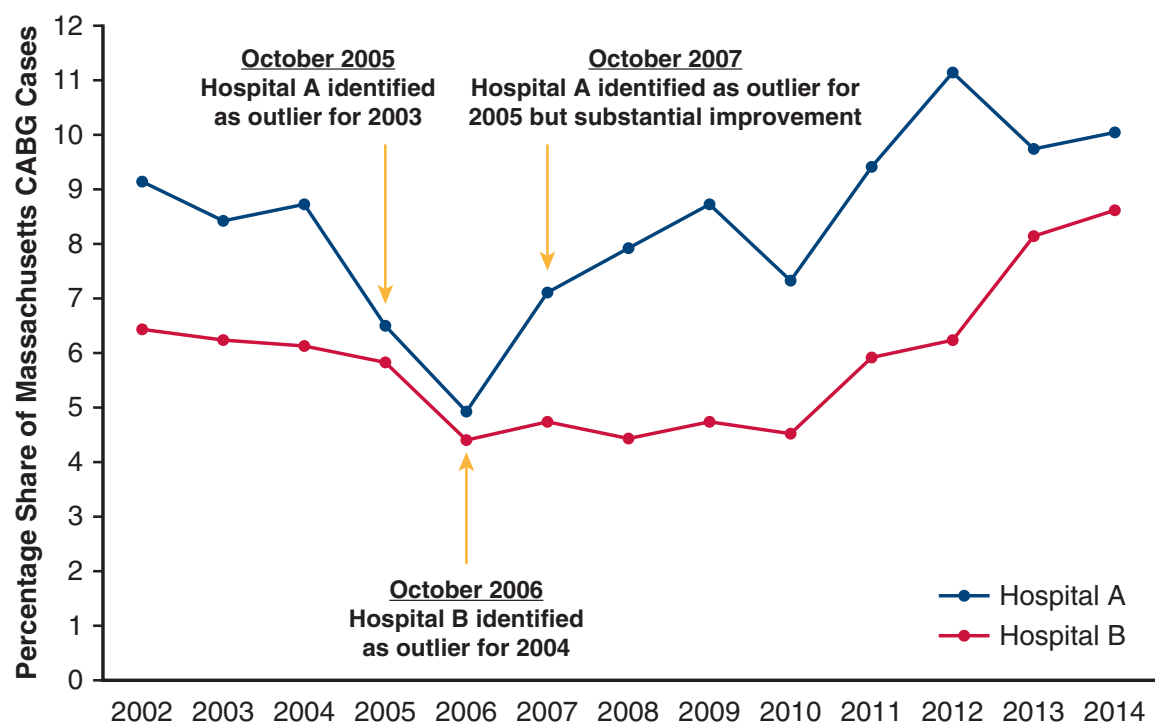

FIGURE 5. Outlier designation and percentage share of total Massachusetts coronary artery bypass graft $(C A B G)$ cases. Following initial outlier designation and temporary closure, Hospital A's share of Massachusetts CABG cases decreased. After implementation of numerous changes, their outcomes improved and their percentage share of Massachusetts CABG cases rebounded in 2007, steadily increasing thereafter despite their second identification as an outlier. Hospital B experienced growth in its share of Massachusetts CABG volume the year following its outlier designation; this percentage then stabilized for 4 years and subsequently increased. 


\section{Change in Hospital Shares of Massachusetts CABG Cases}

2003 - 2014

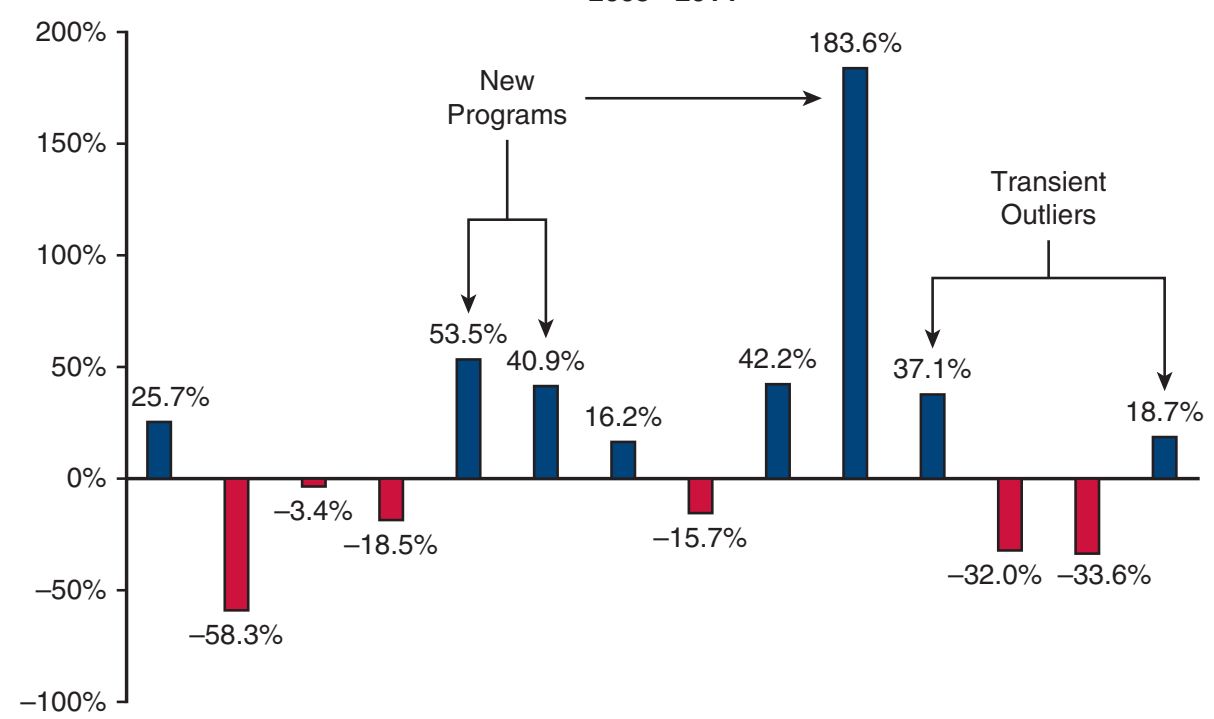

FIGURE 6. Hospital-specific percentage share of total Massachusetts coronary artery bypass graft (CABG) cases, 2003 versus 2014 . Between 2003 and 2014,8 of 14 Massachusetts adult cardiac surgery programs experienced volume growth, including both programs that had been transient outliers. Relative volume shifts among hospitals were more related to initiation of 3 new cardiac surgery programs, which drew volume from existing programs, and with altered referral patterns at several hospitals due to leadership and staff changes.

Massachusetts and STS national rates were similar at the beginning of the public reporting experience (Figure 2, A). However, a direct causal association cannot be inferred from these data, and there are numerous other confounders. For example, Massachusetts also has a longstanding Determination of Need (referred to in other states as Certificate of Need) program, which some states use to restrict the number of hospitals offering certain high cost services ${ }^{26,27}$; in Massachusetts, this resulted in relatively fewer but higher volume cardiac surgery programs. Furthermore, most Massachusetts cardiac surgery units are based in major academic centers or their affiliates. Both higher volume and teaching intensity have been associated with improved health care outcomes. ${ }^{28-32}$

Risk aversion is the most frequently discussed and troubling unintended consequence of public reporting, ${ }^{4,5}$ and this is another potential explanation for lower observed mortality rates in Massachusetts. Risk aversion is typically described as the inappropriate denial of care to high-risk patients who may benefit most from interventions. Not fully trusting the adequacy of risk-adjustment, some providers may be concerned that the anticipated worse outcomes of very high-risk patients will be reflected in their report card scores, thereby harming their practices and reputations. Although the existence and extent of this phenomenon was vigorously debated in the early New York and Pennsylvania CABG public reporting experience, the overall evidence for risk aversion in cardiac surgery is inconclusive, although it is well documented in PCI for complicated acute myocardial infarction. ${ }^{4,5,33-35}$

In the current study, the lower odds of several important risk factors in Massachusetts (eg, shock, emergent/ emergent-salvage, and reoperation) could reflect risk aversion as a potential explanation for the lower observed CABG mortality in Massachusetts compared with the rest of the United States. However, peer-adjudication of risk factors in Massachusetts likely contributed in part to these lower prevalences, both by educating surgeons and data managers regarding definitional nuances, and when necessary by downcoding of submitted data. Other more common risk factors (eg, advanced age, low EF, diabetes, and PVD) had higher or similar prevalences in Massachusetts; temporal trends for many risk factors were no different.

When compared with relatively stable national [STS] rates, decreasing Massachusetts expected mortality from 2003 to 2007 could also be interpreted as supporting risk aversion. However, using identical STS risk models, MA [STS] expected mortality rates were significantly higher than national [STS] rates for this period, although declining, and similar from 2008 onward, which argues against risk aversion. The timeline of Massachusetts public reporting provides useful context for these observations. Massachusetts reporting legislation was passed in 2000 and immediately energized the cardiac surgery community. Two years of anticipation preceded the first year (2002) in which data were actually collected and analyzed. In this context, 
the significantly higher expected mortality rates for Massachusetts (MA [STS]) compared with national [STS] during the early years of public reporting, when there was maximum hospital and surgeon anxiety) seems inconsistent with substantial risk averse behavior.

The increase in MA [STS] observed mortality after 2011 could simply represent regression to the mean after exceptionally low 2011 observed rates. However, there was also a temporal association with phasing out of surgeon-level reporting during the preceding years, which some would argue made surgeons less reluctant to accept very highrisk patients.

Overall, our empirical findings are conflicting and inconclusive regarding risk aversion, at least at the aggregate level. Available Massachusetts data provide no insights regarding individual patient-level decisions, although anecdotal evidence suggests this phenomenon does sometimes occur, even if not at a detectable frequency within the CABG population.

Surgeon and data manager involvement with and support of the Massachusetts public reporting program were critical to its success. For example, Massachusetts' peer adjudication provided additional coding review beyond standard STS audit processes and could be a model for other states and regions. Over time, progressive decreases in cases submitted with selected high-risk preoperative variables, and fewer changes in these adjudicated variables and in cases coded CABG + other, suggest the educational value of this exercise. The greatest divergence between adjudicated Mass-DAC risk factor coding and data submitted directly to STS occurred in the early years of Massachusetts public reporting. This probably reflects the initial coding inexperience of Massachusetts data managers and surgeons (most of whom had not previously participated in the STS Database) as well as some less precise STS variable definitions in earlier years. The Massachusetts peer adjudication process educated all stakeholders regarding optimal coding practices and nuances. It also made them aware that their coding would be adjudicated by peers, making intentional upcoding less likely. Contemporaneously, national STS resources to assist data managers with coding issues were expanded, and STS external audit processes became more robust. In the 2016 external national audit report of the STS ACSD, auditors agreed with submitted coding of cardiogenic shock, myocardial infarction timing, and status (ie, elective, urgent, emergent, or emergent/salvage) in $99.68 \%, 97.59 \%$, and $97.63 \%$ of charts audited, respectively. Thus, because of both Massachusetts and national initiatives, coding for high-risk variables in these 2 data sources progressively converged and became more accurate, although there is a persistently lower prevalence of several such variables in Massachusetts.

Mass-DAC case completeness and mortality verification confirm that hospitals were not hiding cases or deaths; they demonstrate the utility of linking clinical registry data to state and national administrative sources for external validation.

The tendency for outliers to become risk averse, previously documented for PCI, ${ }^{4,5,33,36}$ was transient and inconsistent in our study. Within a few years after outlier designation, expected mortality rates at both Massachusetts outlier programs had stabilized around the state average.

Similar to New York findings, ${ }^{37-41}$ only 1 of the 2 outlier hospitals experienced a negative influence on its share of Massachusetts CABG cases and that effect was transient. Many factors besides objective outcomes influence patient selection of a provider, including the recommendations of the referring physicians, family, and friends; geographic preferences; differences in copays; and limited choices available in their insurance plan. Relative volume shifts among hospitals were more related to initiation of 3 new cardiac surgery programs, which drew volume from existing programs, and with altered referral patterns at several hospitals due to leadership and staff changes. If underlying causes of outlier designation are addressed quickly and effectively, referral impact should be limited and transient.

\section{Limitations}

One major motivation for the Commonwealth of Massachusetts to mandate participation in the STS National Database was the prior lack of credible data regarding cardiac surgical outcomes. Thus, we have no data on risk factors or outcomes before the institution of the public reporting program, which limits our ability to comment upon comparisons of Massachusetts and national data before 2002.

During the study period, STS practice was to regard postdischarge patients with unknown or missing 30-day vital status as alive, which could potentially introduce bias. However, in-hospital deaths are recorded with near $100 \%$ completeness and these represent the vast majority of 30day deaths. STS simulations (available upon request) suggest that any errors introduced by the false assumption that a patient with missing or unknown 30-day status is alive have negligible influence on hospital mortality results compared with random sampling error. Also, given 100\% complete 30-day vital status for Massachusetts patients, if any STS national patient were misclassified as alive, correcting this would only increase the apparent mortality advantage for Massachusetts.

We do not have data on patients who may have not been offered surgery because of their high risk, which limits our assessment of risk aversion.

\section{CONCLUSIONS}

Mandatory Massachusetts public reporting did not disproportionately limit overall access to cardiac surgery 
services, as demonstrated by overall CABG volume trends from 2002 to 2014. Moreover, using comparable data and risk models, CABG outcomes in Massachusetts from 2003 to 2014 were consistently and significantly superior to national [STS] results. However, because extensive longitudinal data are unavailable before the initiation of Massachusetts public reporting, we cannot assume a causal association of report cards and superior outcomes. Finally, evidence for risk aversion was inconsistent and inconclusive. These findings, together with previous studies from New York and from STS, support the continued study of public reporting as 1 mechanism to assist patients in selecting providers and to promote optimal surgical outcomes.

Our experience suggests that surgeons in public reporting states may benefit from the establishment of formal peer organizations (such as the MA STS) that can serve as their interface with state regulatory agencies. This allows them to be part of the measure development process, to provide clinical context for problematic statistical results, and to offer remedial recommendations for outlier programs. Robust surgeon involvement in the public reporting process was also evident in the Massachusetts peer adjudication process for risk factor coding. This provides valuable oversight and education regarding appropriate coding practices, reassures surgeons and hospitals regarding data integrity, and may mitigate risk aversion by fostering provider trust in the system. It is most easily operationalized at the state or regional levels.

Finally, the Massachusetts experience demonstrates that if outlier hospitals implement appropriate programmatic, structural, leadership, and staff changes, the negative consequences of their outlier status may be temporary and remediable.

\section{Webcast}

You can watch a Webcast of this AATS meeting presentation by going to: https://aats.blob.core.windows.net/ media/18Apr30/20ABC\%201.Plenary \%20Sessions/S59\% 20-\%20Part\%202/S59_4.mp4.

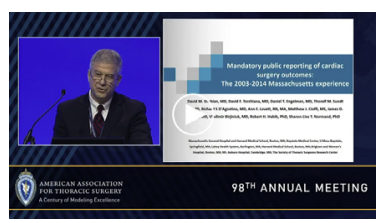

\section{Conflict of Interest Statement}

Drs Shahian, Torchiana, D’Agostino, Engelman, Rawn, and Birjiniuk have been unpaid, volunteer leaders in the development and implementation of the Massachusetts public reporting system. Dr Normand has been a paid leader for and Ms Lovett and Mr Cioffi are employees of Mass-DAC, the entity that administered the Massachusetts cardiac surgery public reporting program during the term of this study. Dr Habib is director of the Society of Thoracic Surgeons Research Center. All other authors have nothing to disclose with regard to commercial support.

The authors thank the Massachusetts Department of Public Health for the use of their data, and the Society of Thoracic Surgeons for providing data from its Adult Cardiac Surgery Database.

\section{References}

1. Shahian DM, Edwards FH, Jacobs JP, Prager RL, Normand SL, Shewan CM, et al. Public reporting of cardiac surgery performance: part 1-history, rationale, consequences. Ann Thorac Surg. 2011;92(3 Suppl):S2-11.

2. Shahian DM, Edwards FH, Jacobs JP, Prager RL, Normand SL, Shewan CM, et al. Public reporting of cardiac surgery performance: part 2-implementation. Ann Thorac Surg. 2011;92(3 Suppl):S12-23.

3. Shahian DM, Normand SL, Friedberg MW, Hutter MM, Pronovost PJ. Rating the raters: the inconsistent quality of health care performance measurement. Ann Surg. 2016;264:36-8.

4. Shahian DM, Jacobs JP, Badhwar V, D'Agostino RS, Bavaria JE, Prager RL. Risk aversion and public reporting. part 1: observations from cardiac surgery and interventional cardiology. Ann Thorac Surg. 2017;104:2093-101.

5. Shahian DM, Jacobs JP, Badhwar V, D'Agostino RS, Bavaria JE, Prager RL. Risk aversion and public reporting. Part 2: mitigation strategies. Ann Thorac Surg. 2017; 104:2102-10.

6. Hannan EL, Cozzens K, King SB III, Walford G, Shah NR. The New York State cardiac registries: history, contributions, limitations, and lessons for future efforts to assess and publicly report healthcare outcomes. J Am Coll Cardiol. 2012;59: 2309-16.

7. Schneider EC, Epstein AM. Use of public performance reports: a survey of patients undergoing cardiac surgery. JAMA. 1998;279:1638-42.

8. Schneider EC, Epstein AM. Influence of cardiac-surgery performance reports on referral practices and access to care-a survey of cardiovascular specialists. $N$ Engl J Med. 1996;335:251-6.

9. Harlan BJ. Statewide reporting of coronary artery surgery results: a view from California. J Thorac Cardiovasc Surg. 2001;121:409-17.

10. Shahian DM, Grover FL, Prager RL, Edwards FH, Filardo G, O'Brien SM, et al The Society of Thoracic Surgeons voluntary public reporting initiative: the first 4 years. Ann Surg. 2015;262:526-35.

11. Shahian DM, Jacobs JP, Edwards FH, Brennan JM, Dokholyan RS, Prager RL, et al. The Society of Thoracic Surgeons National database. Heart. 2013;99:1494-501.

12. Shahian DM, Jacobs JP. Health services information: lessons learned from the Society of Thoracic Surgeons National database. In: Sobolev B, Levy A, Goring S, eds. Data and measures in health services research. Boston: Springer US; 2016:1-24.

13. Massachusett Department of Health. Cardiac services and treatments. Available at: https://www.mass.gov/service-details/cardiac-treatment-services. Accessed January 8, 2019.

14. Green J, Wintfeld N. Report cards on cardiac surgeons. Assessing New York State's approach. N Engl J Med. 1995;332:1229-32.

15. Chassin MR, Hannan EL, DeBuono BA. Benefits and hazards of reporting medical outcomes publicly. N Engl J Med. 1996;334:394-8.

16. The Society of Thoracic Surgeons. Homepage. Available at: www.sts.org. Accessed January 8, 2019.

17. The STS National database. Available at: http://www.sts.org/registries-researchcenter/sts-national-database. Accessed January 8, 2019.

18. Massachusetts Data Analysis Center. Adult coronary artery bypass graft surgery FY14 annual report. Available at: https://www.mass.gov/files/documents/2017/ 12/14/cabg-fy2014.pdf. Accessed January 8, 2019.

19. Barringhaus KG, Zelevinsky K, Lovett A, Normand SL, Ho KK. Impact of independent data adjudication on hospital-specific estimates of risk-adjusted mortality following percutaneous coronary interventions in massachusetts. Circ Cardiovasc Qual Outcomes. 2011;4:92-8.

20. Shahian DM, O'Brien SM, Filardo G, Ferraris VA, Haan CK, Rich JB, et al. The Society of Thoracic Surgeons 2008 cardiac surgery risk models: part 1 -coronary artery bypass grafting surgery. Ann Thorac Surg. 2009;88(1 Suppl):S2-22. 
21. O'Brien SM, Shahian DM, Filardo G, Ferraris VA, Haan CK, Rich JB, et al. The Society of Thoracic Surgeons 2008 cardiac surgery risk models: part 2-isolated valve surgery. Ann Thorac Surg. 2009;88(1 Suppl):S23-42.

22. Shahian DM, O'Brien SM, Filardo G, Ferraris VA, Haan CK, Rich JB, et al. The Society of Thoracic Surgeons 2008 cardiac surgery risk models: part 3-valve plus coronary artery bypass grafting surgery. Ann Thorac Surg. 2009;88(1 Suppl):S43-62.

23. Shahian DM, Jacobs JP, Badhwar V, Kurlansky PA, Furnary AP, Cleveland JC Jr, et al. The Society of Thoracic Surgeons 2018 adult cardiac surgery risk models: part 1-background, design considerations, and model development. Ann Thorac Surg. 2018;105:1411-8.

24. O'Brien SM, Feng L, He X, Xian Y, Jacobs JP, Badhwar V, et al. The Society of Thoracic Surgeons 2018 adult cardiac surgery risk models: part 2-statistical methods and results. Ann Thorac Surg. 2018;105:1419-28.

25. O'Brien SM, Shahian DM, DeLong ER, Normand SL, Edwards FH, Ferraris VA, et al. Quality measurement in adult cardiac surgery: part 2—statistical considerations in composite measure scoring and provider rating. Ann Thorac Surg. 2007; 83(4 Suppl):S13-26.

26. Ho V, Ku-Goto MH, Jollis JG. Certificate of Need (CON) for cardiac care: controversy over the contributions of CON. Health Serv Res. 2009;44(2 Pt 1): 483-500.

27. DiSesa VJ, O'Brien SM, Welke KF, Beland SM, Haan CK, VaughanSarrazin MS, et al. Contemporary impact of state certificate-of-need regulations for cardiac surgery: an analysis using the Society of Thoracic Surgeons' National Cardiac Surgery Database. Circulation. 2006;114:2122-9.

28. Birkmeyer JD, Stukel TA, Siewers AE, Goodney PP, Wennberg DE, Lucas FL. Surgeon volume and operative mortality in the United States. $N$ Engl J Med. 2003;349:2117-27.

29. Birkmeyer JD, Siewers AE, Finlayson EVA, Stukel TA, Lucas FL, Batista I, et al. Hospital volume and surgical mortality in the United States. N Engl J Med. 2002; 346:1128-37.

30. Shahian DM, Normand SL. The volume-outcome relationship: from Luft to Leapfrog. Ann Thorac Surg. 2003;75:1048-58.

31. Burke LG, Frakt AB, Khullar D, Orav EJ, Jha AK. Association between teaching status and mortality in US Hospitals. JAMA. 2017;317:2105-13.

32. Shahian DM, Liu X, Meyer GS, Torchiana DF, Normand SL. Hospital teaching intensity and mortality for acute myocardial infarction, heart failure, and pneumonia. Med Care. 2014:52:38-46.

33. Waldo SW, McCabe JM, O'Brien C, Kennedy KF, Joynt KE, Yeh RW. Association between public reporting of outcomes with procedural management and mortality for patients with acute myocardial infarction. J Am Coll Cardiol. 2015;65:1119-26.

34. McCabe JM, Waldo SW, Kennedy KF, Yeh RW. Treatment and outcomes of acute myocardial infarction complicated by shock after public reporting policy changes in New York. JAMA Cardiol. 2016;1:648-54.

35. Joynt KE, Blumenthal DM, Orav EJ, Resnic FS, Jha AK. Association of public reporting for percutaneous coronary intervention with utilization and outcomes among Medicare beneficiaries with acute myocardial infarction. JAMA. 2012; 308:1460-8.

36. McCabe JM, Joynt KE, Welt FG, Resnic FS. Impact of public reporting and outlier status identification on percutaneous coronary intervention case selection in Massachusetts. JACC Cardiovasc Interv. 2013;6:625-30.

37. Chassin MR. Achieving and sustaining improved quality: lessons from New York State and cardiac surgery. Health Aff (Millwood). 2002;21:40-51.

38. Jha AK, Epstein AM. The predictive accuracy of the New York State coronary artery bypass surgery report-card system. Health Aff (Millwood). 2006;25: 844-55.

39. Mukamel DB, Weimer DL, Mushlin AI. Interpreting market share changes as evidence for effectiveness of quality report cards. Med Care. 2007;45: 1227-32.

40. Mukamel DB, Mushlin AI. The impact of quality report cards on choice of physicians, hospitals, and HMOs: a midcourse evaluation. Jt Comm J Qual Improv. 2001;27:20-7.

41. Mukamel DB, Mushlin AI. Quality of care information makes a difference: an analysis of market share and price changes after publication of the New York State Cardiac Surgery Mortality Reports. Med Care. 1998; 36:945-54.

Key Words: public reporting, CABG mortality, risk adjustment

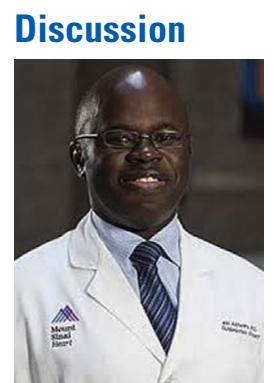

Dr Anelechi C. Anyanwu (New York, $N Y$ ). This excellent analysis from the state of Massachusetts evaluates the trends and influence of public reporting The hospital survival after coronary bypass surgery was consistently lower than the Society of Thoracic Surgeons (STS) average, as you have seen - that's why it's a higher predicted mortality-there were no obvious negative effects of public reporting, and only 2 hospitals were sanctioned in the time period for poor outcomes. None has been sanctioned in the past 10 years, none of them lost their market share, and this supports the positive value to the whole exercise. The analysis does, however, broach on several broad issues regarding public reporting, ranking, and comparison of centers and surgeons and evaluation of surgical outcomes, and I would like to develop some of these further.

So my first question regards the low observed mortality in Massachusetts. In 2003 when public reporting started, you had a mortality that was the same as the STS database, but in 2005, 2 years later and every year since, you have had a mortality lower than the STS database and you have maintained an observed to expected ratio about 0.6 to 0.8 and a mortality rate consistently below $1.7 \%$ compared with $2 \%$ nationally. That implies someone's decision on public reporting. Indeed in New York State where we also have public reporting, our mortality rate for the last reportable year was $1.5 \%$, also below the STS.

So setting aside risk aversion, which we will come to, can you suggest mechanisms as to how public reporting could lead to better outcomes of surgery?

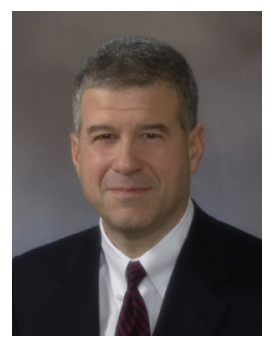

Dr Shahian (Boston, Mass). That is an excellent question that the published literature does not answer conclusively.

Before I answer your question, I would like to make a subtle but important clarification, which is the distinction between ranking and rating. Ranking implies a direct comparison of the results of 2 hospitals, and that is not permissible when using indirectly standardized results as we do in Massachusetts and nationally. Rather, we rate hospitals by comparing their risk-adjusted performance for their case mix compared with what would have been expected based on the national benchmark population of providers. This distinction seems arcane but it's actually very important and something we always try to emphasize.

We don't have comparative data before 2002 to 2003 , which is a limitation of our study. However, you are correct that in these first years of Massachusetts public reporting our mortality rates were close to national STS rates, then markedly diverged. 
As to why public reporting in general might improve outcomes, knowledge is power. With knowledge of your own results and the desire to excel, which most people in this room have, these data are a great stimulus and guide to performance improvement. They are also a lever for cardiac surgical programs to use with hospital administrations to get the resources they need to make their programs better.

Finally, we have a very small number of programs in this country that consistently (not just 1 reporting period) underperform. Public reporting appropriately identifies such providers and increases the pressure on them to improve or close.

Dr Anyanwu. So then should all states and countries embark on public reporting, in your opinion?

Dr Shahian. If you can do it responsibly_and I would suggest that the Massachusetts and STS experiences are good models for mandatory and voluntary reportingand with appropriate methodology, then I think it is an ethical imperative, It's a way to provide patients with additional objective information to aid them in the selection of a provider. It is certainly not the only factor they should consider, but it can be very useful in deciding where to go for surgery.

Dr Anyanwu. But your positive experience has not been universal. As you know, in the United Kingdom, for example, there has been increasing outcry against public reporting with many cardiac surgeons reporting having observed or practiced risk aversion, surgeons have lost their jobs due to scrutiny of results, surgical training is suffering because the consultants are reluctant to allow trainees to operate. So these are likely consequences of surgeon-level reporting, which occurs in the United Kingdom and in the United States.

But I know that in Massachusetts you have stopped doing surgeon-level reporting. Can you tell us why you stopped and whether as societies we should push against any further surgeon level reporting for future systems?

Dr Shahian. Surgeon-level public reporting for coronary artery bypass grafting was discontinued in Massachusetts primarily because the interventional cardiology community did not want operator-specific reporting for percutaneous coronary intervention, and there was a desire to have similar approaches to these 2 initiatives.

In general, what are the pros and cons of surgeon-specific reporting? On the pro side, we know that there is variation in surgeon outcomes, even within the same program. We are not a fungible commodity, and patients have a right to know the results of their prospective caregivers if they can be accurately determined. Secondly, patients and referring physicians often pick specific surgeons, not just hospitals, for elective or semielective procedures. A unique relationship is subsequently established between the patient and their surgeon, and the patient expects that that surgeon will oversee and optimize all aspects of the care required for a cardiac surgical patient in their institution. This is a very special relationship that doesn't exist between the patient and any other component of that team.

Now, on the con side, it's more statistically challenging to estimate performance for a surgeon just because of the smaller number of cases, which is why we have developed an STS multiprocedural, multidomain composite measure for adult cardiac surgeons. The other potential problem with surgeon-level reporting is that it is surgeons, not hospitals, who make the decision about whether a patient is offered surgery or not. So if you are concerned about risk aversion, I think reporting at the surgeon level has more potential for harm. However, as a counter to that risk aversion argument, there are also data showing that in a public reporting environment, higher-risk patients tend to ultimately receive their operative care from more capable surgeons, although they may have been turned down by less experienced surgeons. This is exactly what you would like to have happen.

Dr Anyanwu. So unintended and intended consequences of public reporting can lead to disruption of individual carriers, teams, hospitals, and while you have succeeded and have already taken those 2 outlier hospitals, that's not necessarily the experience elsewhere. So when we say a surgeon or a hospital is an outlier, we have to be pretty sure that that's the case.

So that brings us to the tools that we use to measure them. In your study you took extra effort to validate a sample of cases. You adjudicated all deaths, you adjudicated all major risk factors, and that ensured a very accurate data set. In contrast, the STS, to which you compare, does none of the above, or in a very limited fashion. And I believe that the difference in prevalence of the key risk factors like emergent status and shock that you showed were because your data are very adjudicated.

Do you think we should be using nonadjudicated data sources like the STS or administrative data sources to rate centers or surgeons or to rank centers or surgeons?

Dr Shahian. I have to disagree with the premise of your statement. The data in the STS database are extraordinarily well audited, more so than virtually any other health care data of which I am aware. Using a highly respected external auditor, we now audit $10 \%$ of all programs every year. They review all major risk factors and outcomes.

I just reviewed our audit data for the last several years. The agreement rates for particularly high-risk variables such as cardiogenic shock, emergency status, were all in the $95 \%$ to $99 \%$ range.

Dr Anyanwu. Sorry. What I am saying is your data are more accurate, so that's the reason why you have a low incidence.

Dr Shahian. I'm talking about the STS national data.

Dr Anyanwu. The STS national data may not be as accurate as yours. 
Dr Shahian. No, I'm talking about the STS.

Dr Anyanwu. Okay.

Dr Shahian. Ten percent of STS programs are audited every year, about 120 programs last year and roughly 80 data elements from each chart, with $95 \%$ to $99 \%$ plus agreement rates for most high-risk variables. I am very confident about current STS data.

STS also provides the opportunity for data managers and surgeons to access the leaders of the database, essentially on a real-time basis, to ask questions about coding, including conference calls every week addressing these questions. We have a national STS Advances in Quality and Outcomes conference annually devoted to teaching data managers how to code accurately. Overall, I'm quite confident with the accuracy of the STS database, although we are always trying to improve.

Our additional peer adjudication of high-risk variables in Massachusetts has been a valuable adjunct to educate data managers and surgeons about the nuances of certain variables, and to reassure all stakeholders about the integrity and accuracy of the data. It could easily be reproduced by any state or regional cardiac surgical organization.

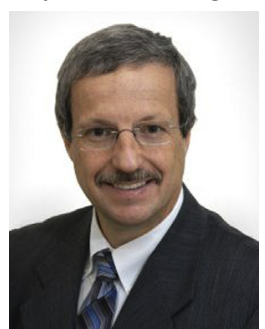

Dr Oz Shapira (Jerusalem, Israel). It's humbling to give any comments on $\mathrm{Dr}$ Shahian's presentation, but I congratulate you and the authors for another excellent study. I was part of the Massachusetts database, and I want to ask you a specific question, and I fully believe in public reporting of a surgeon's performance. But you talk mostly about risk aversion. There is another very important risk in public reporting, which is teaching aversion, particularly in Massachusetts when you have teaching and nonteaching hospitals, not maybe a corollary to risk aversion.

Are you looking to teaching aversion in your data and trying to separate from teaching and nonteaching hospitals and correlate it with risk aversion?

Dr Shahian. A wonderful point, Oz. Unfortunately, I have no data on that issue. Although public reporting may impact the willingness of surgeons to take residents through tough cases, the increasing complexity and severity of the cases being encountered in cardiac surgery are also a challenging issue in this regard.

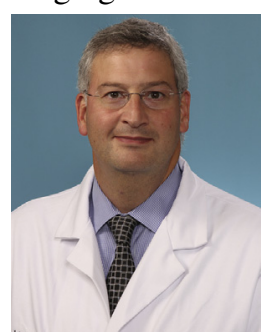

Dr Benjamin Kozower (Charlottesville, $\mathrm{Va}$ ). Thank you for an outstanding presentation and for all you have done in this field. I would like to ask a follow-up question about risk aversion. Around the same time that your data were collected, there were several important papers published using Massachusetts data. They showed that for acute cardiogenic shock where percutaneous coronary intervention might be most beneficial, it was used less frequently following public reporting of these high risk cases. So, it's hard for me to reconcile this and I remain concerned that risk aversion exits and is related to public reporting.

Dr Shahian. Good point, Benj. I have had an opportunity over the past year to try to ferret out all the available information in the literature about risk aversion. The evidence for this behavior in interventional cardiology is much stronger and much more consistent, probably because a lot of the cardiogenic shock, postmyocardial infarction patients who might have been operated on in the past are all going to the cath lab now. So the interventional cardiologists have to deal with these very challenging ethical questions. Based on my review of the evidence, there is no question that there is risk aversion in the percutaneous coronary intervention community.

In cardiac surgery I would say the evidence is mixed. There are surveys asking surgeons if they have practiced risk aversion, and they will admit to it. However, if you look at aggregate data, such as the Massachusetts or national STS data, it's hard to conclusively demonstrate risk aversion. Of course, those aggregate data do not tell you what's going on at the level of an individual patient decision.

Dr Kozower. And in your state data source, do you have any way to link the short-term outcomes to long-term outcomes?

Dr Shahian. We don't, Benj, but that is something that we are actually very close to being able to do in STS through linkages with the National Death Index. Also, as short-term mortality rates have fallen to the $1 \%$ range, mortality alone is not an adequate discriminator of quality. That's one reason why we look at complications as well in the STS composite measures. But I agree we need to look at the long-term durability of what we do-how are those patients doing 5 years and 10 years out.

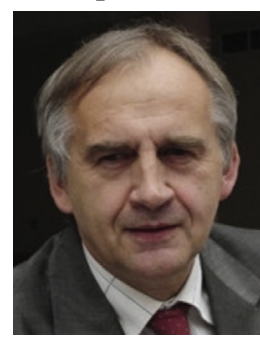

Dr Marian Zembala (Zabrze, Poland). Thank you so much for this message, but when you look for the trends in patients who are in cardiogenic shock for the past 10 to 12 years, you will be surprised. We are still almost at the same level like 10 to 15 years ago despite the assist devices, echo, and other points. And the lessons, what we have learned and we realize in Poland, we separate the group of cardiogenic patients and patients as postinfarction like ST-elevation myocardial infarction, for example, and present separate death. In this situation you save the patient, you are active for teaching and active to accept this patient for also surgical and cardiac revascularization, but you are not afraid in a very obsessive way to disturb your average very good results. I think you will always compromise, because patient is first and you can keep quality. That is my message, that is my intention. 
Dr Shahian. So if I understand you correctly, are you arguing for exclusion of very high-risk patients from public reporting?

Dr Zembala. Not exclusion but just present separately. That's different. Then you can present deaths, because you have centers that avoid this type of patient and you have centers which 24 hours work on all types of patients, including cardiogenic shock, and then this situation you can compromise both and the patient's life is first.

Dr Shahian. We have not done that in Massachusetts or STS nationally for cardiac surgery, but it's a reasonable suggestion. It is done in Massachusetts percutaneous coronary intervention public reporting, where they have separate reports for more elective cases versus the shock or ST-elevation myocardial infarction cases.

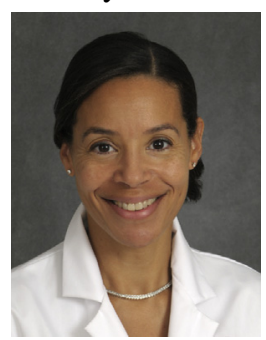

Dr Joanna Chikwe (New York, NY). A slightly broader question about risk aversion driven by this laser focus on 30-day outcomes. Would either of the panelists speak to innovation aversion caused by this laser focus on 30-day outcomes? We heard this morning about data from an entire state where only $5.7 \%$ of coronary artery bypass grafting patients had more than a single arterial conduit. How can we drive practice and innovation that is more focused on our patients' long-term outcomes and not just on the 30-day results?

Dr Shahian. As I mentioned previously, as short-term outcomes progressively improve, getting long-term data to share with patients will be increasingly important, not just survival but also freedom from reinterventions and late complications.

Regarding the stifling of innovation by public reporting, that is a legitimate concern. In Dr Bavaria's STS presidential address 2 years ago, he expressed concerns about how reporting could stifle innovation, because initial results with any new procedure or device may not be optimal. I understand that argument, but at the same time we need to think about this issue from the patient's perspective. We cannot in good conscience utilize new procedures or technologies unless patients understand the potential risks of a suboptimal result. I want to make sure that patients are fully informed and protected as we apply innovative new approaches.

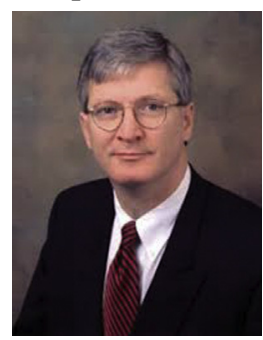

Dr John D. Puskas (New York, NY). David, fascinating presentation. I am going to ask a very pointed question, my friend. When will the STS make a second arterial graft a quality metric? Dr Shahian. We are seriously considering that, John. We are now at about $98 \%$ to $99 \%$ utilization for a single arterial graft, but our multiarterial grafting percentages are abysmal.

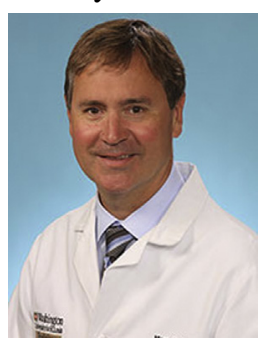

Dr Moon. Dr Anyanwu.

Dr Anyanwu. I think we have to differentiate risk aversion. There is always risk awareness, and I think in public reporting states you have risk awareness. I would be interested to know in Massachusetts whether there were other practice changes in those 10 years. For example, were patients with coronary disease getting a mitral valve repaired to move them away from an isolated coronary category? Were people getting more percutaneous coronary interventions? What happened to all the shock patients who had acute myocardial infarctions in Massachusetts? Did they get left ventricular assist devices? Did they just die? What happened to them?

I think one has to look at risk awareness and look at what happens in the whole big picture as opposed to just in the surgical arena.

Dr Shahian. To answer your specific questions, we have typically reviewed coronary artery bypass grafting + mitral repair operative notes and charts in Massachusetts to be sure these repairs were not being done to remove the patient from the publicly reported, isolated coronary artery bypass graft category. Regarding percutaneous coronary intervention for shock patients, there was a drop in the percentage of such cases when percutaneous coronary intervention public reporting was instituted but this was reversed when a compassionate use variable was added to our risk models to account for extremely high-risk patient presentations.

Just one parting comment on risk aversion. There are 3 things that can happen in a so-called risk averse environment, which I think is better characterized as risk aware2 of those 3 outcomes are positive. The first consequence is the negative consequence we worry most about, which is inappropriate denial of interventions to very high-risk patients. The second consequence, demonstrated in multiple studies, is that in a public reporting environment you get better matching of high-risk patients to programs and surgeons who are more capable, more experienced, have better outcomes, and are generally more suited to taking care of those patients. This is exactly what you would like to have happen. And the third outcome is also positive. The patient with virtually no chance of survival, the hopeless case, is less likely to go to the operating room, which is often the best decision for them and their loved ones.

Thank you very much. 

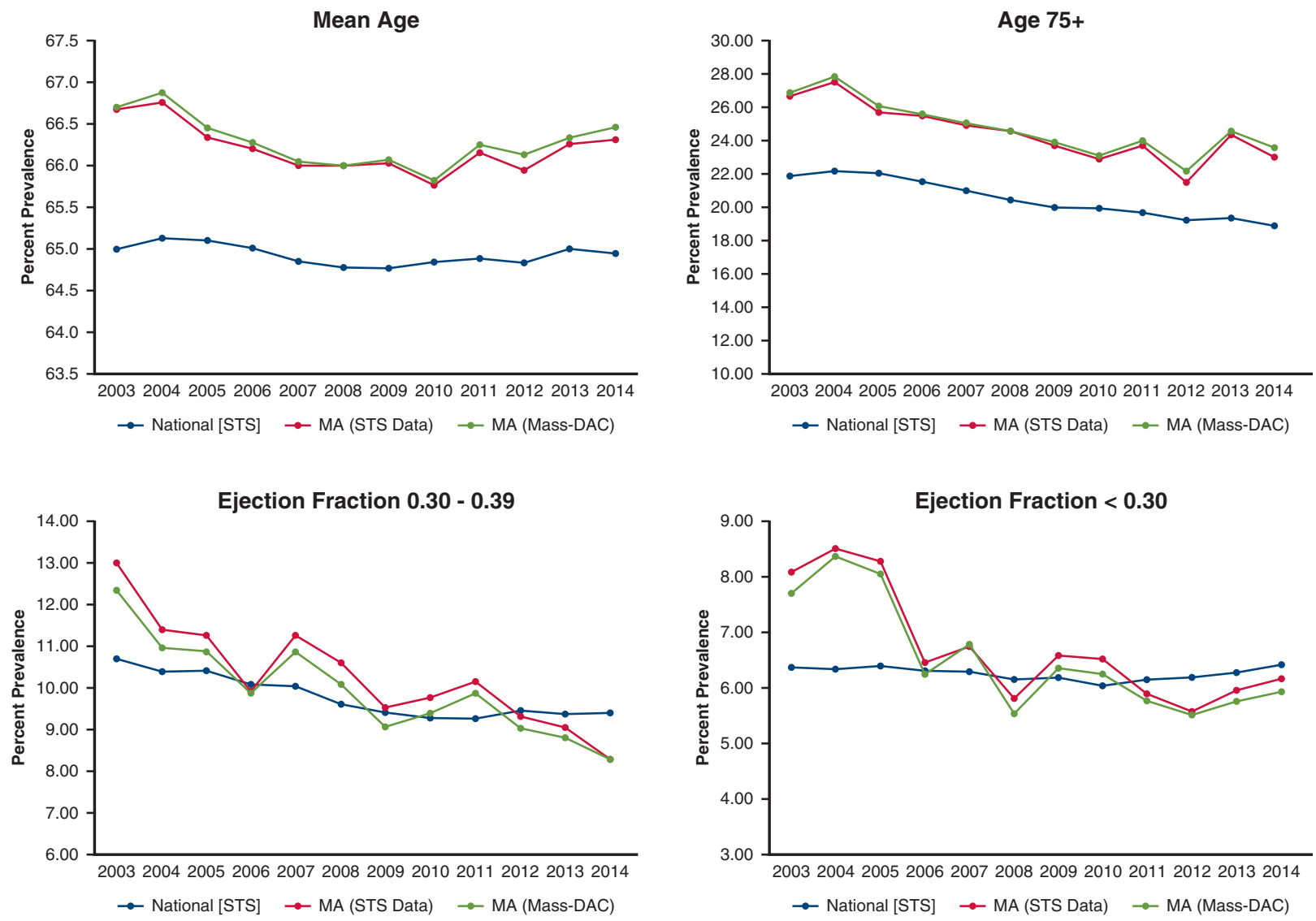

FIGURE E1. Risk prevalence plots for age and ejection fraction. For these 4 risk factors, MA [STS] (MA data submitted directly to STS) and Mass-DAC prevalence rates were virtually superimposable. These rates were generally higher than national STS rates (excluding MA patients). MA and national STS temporal trends in these risk factors were similar except for a sharp decrease in EF $<0.30$ prevalences in MA patients from 2003-2006. STS, Society of Thoracic Surgeons; MA, Massachusetts; Mass-DAC, Massachusetts Data Analysis Center. 

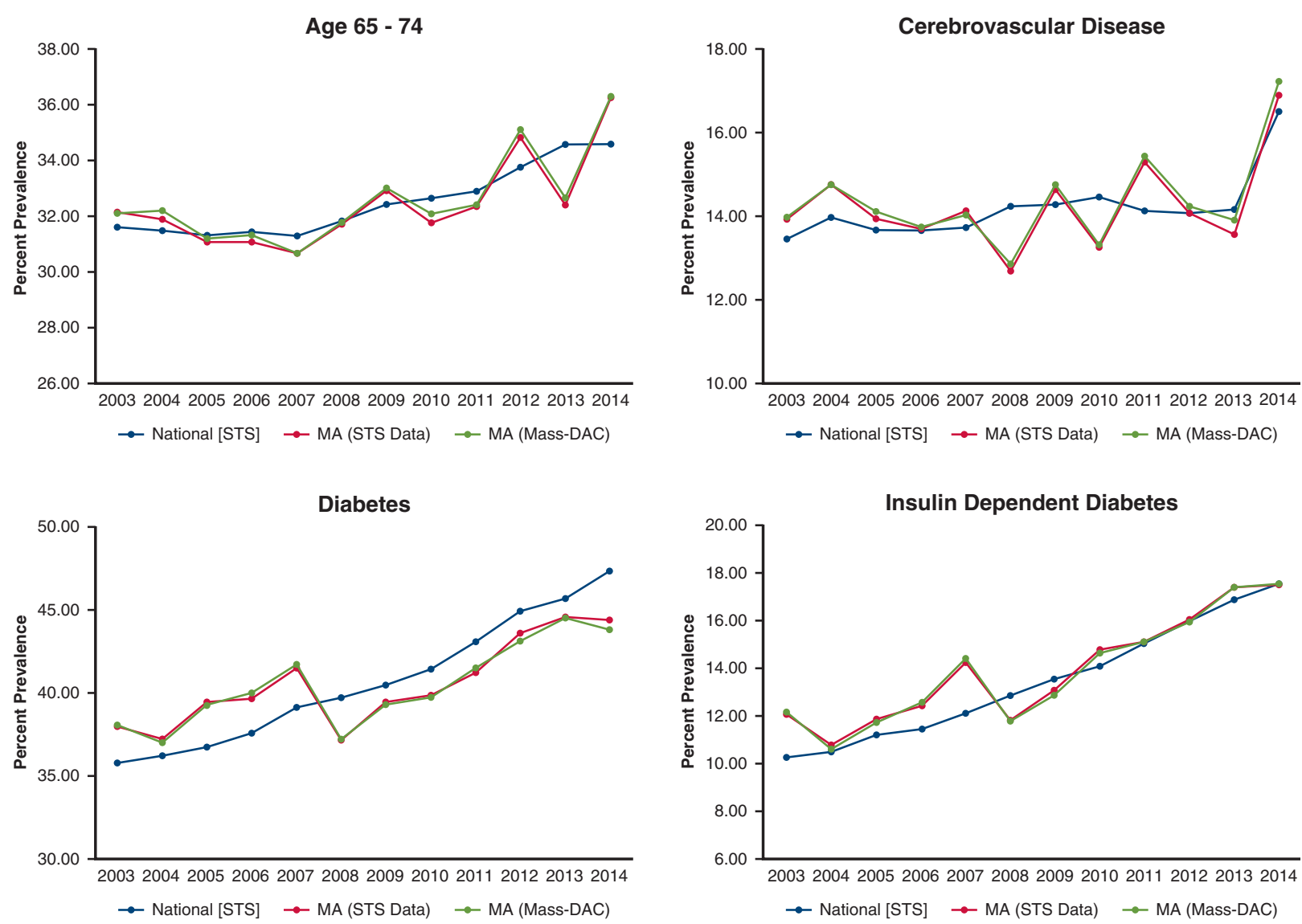

FIGURE E2. Risk prevalence plots for age and comorbid conditions. For these 4 risk factors, MA [STS] (MA data submitted directly to STS) and MassDAC prevalence rates were nearly identical. These rates and their temporal trends were generally similar to those of national STS data (excluding MA patients). STS, Society of Thoracic Surgeons; MA, Massachusetts; Mass-DAC, Massachusetts Data Analysis Center. 

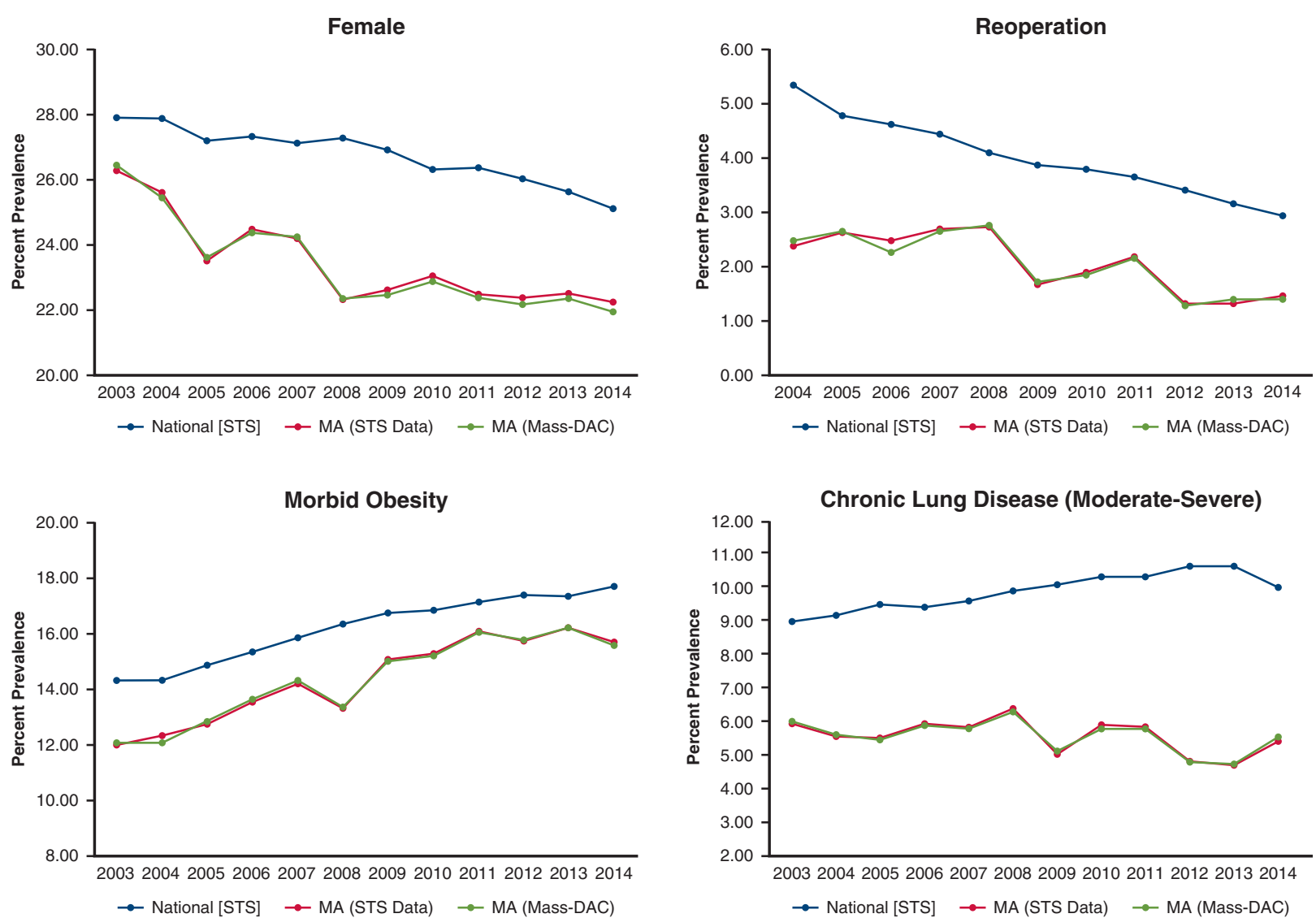

FIGURE E3. Risk prevalence plots for sex and comorbid conditions. For these 4 risk factors, MA [STS] (data submitted directly to STS) and Mass-DAC prevalence data were nearly identical. Massachusetts prevalence rates were consistently less than national STS rates (excluding MA). Temporal trends were similar between Massachusetts and national data for female sex, reoperation, and morbid obesity, but divergent for chronic lung disease (national STS slightly increasing, Massachusetts stable to slightly decreasing). STS, Society of Thoracic Surgeons; MA, Massachusetts; Mass-DAC, Massachusetts Data Analysis Center. 


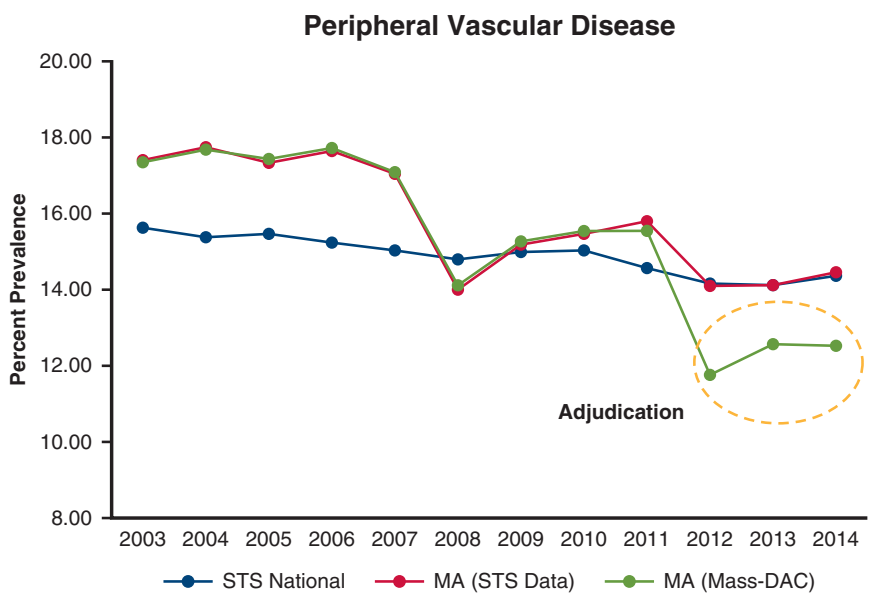

\section{Episodic adjudication}

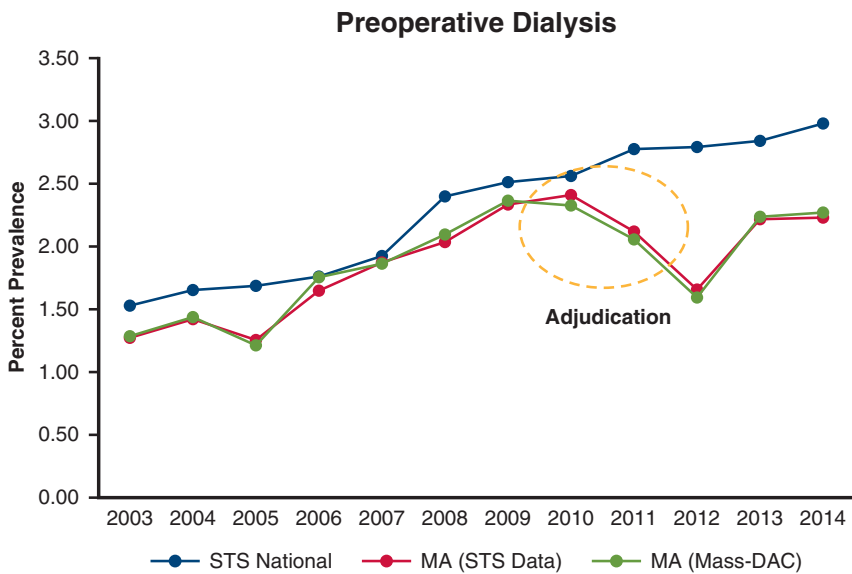

FIGURE E4. Episodic peer adjudication. Peripheral vascular disease and preoperative dialysis underwent additional peer-adjudication only for a few years (circled in the plots). During the period of adjudication, peripheral vascular disease prevalences were lower in Mass-DAC data (additional peer adjudication) than in unadjudicated MA [STS] data or national [STS] data (excluding MA). Preoperative dialysis prevalence rates were virtually identical in adjudicated Mass-DAC data and MA data submitted directly to STS (MA[STS]), and these rates were lower than national [STS] prevalence rates. STS, Society of Thoracic Surgeons; MA, Massachusetts; Mass-DAC, Massachusetts Data Analysis Center. 

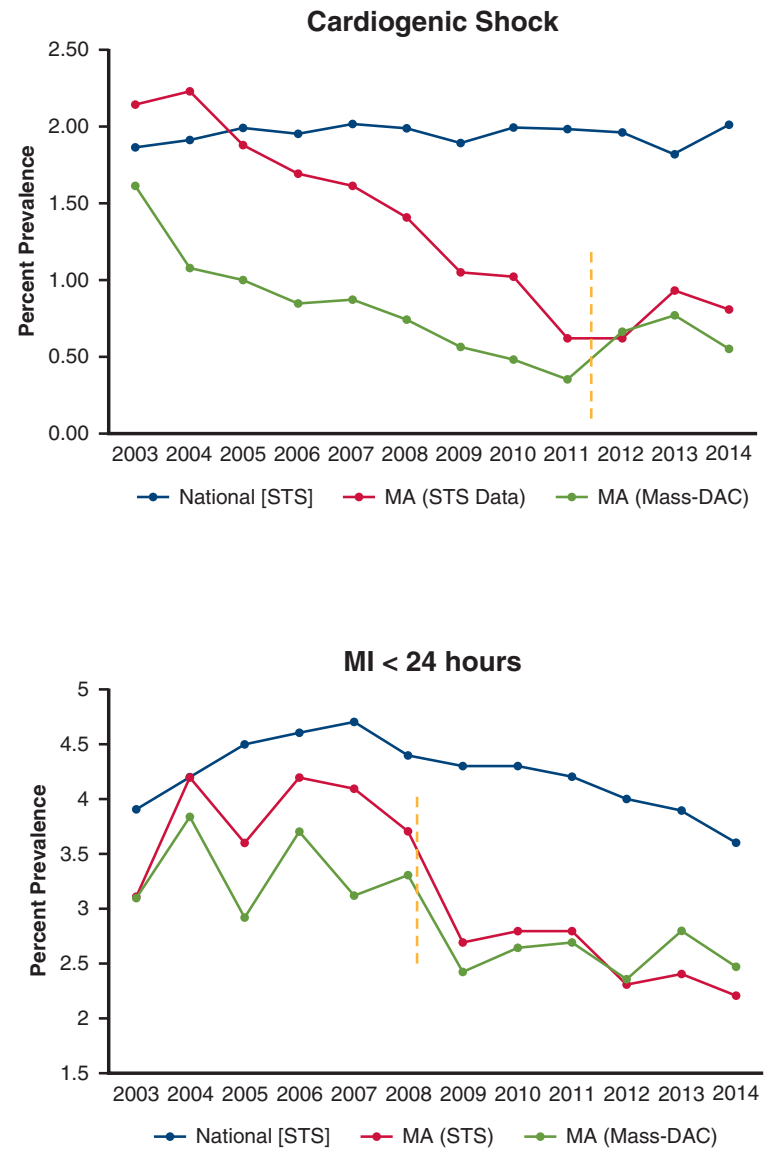

\section{Routinely Peer-Adjudicated Variables}

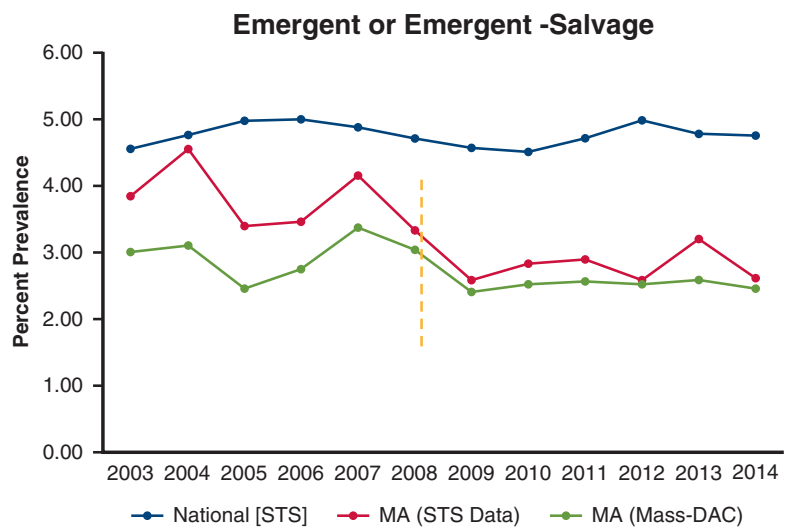

Peer-adjudicated coding differences between Mass-DAC and MA [STS] curves in early years, then converge

FIGURE E5. Routinely peer-adjudicated variables. For all three routinely peer-adjudicated risk factors, Massachusetts Data Analysis Center (Mass-DAC) prevalence rates were lower than MA [STS] rates (submitted directly to STS) in the early years of MA public reporting. With increasing experience and education of data managers and surgeons, the Mass-DAC and MA[STS] rates converged (vertical dotted line) for all 3 risk factors but remained substantially lower than national STS rates (excluding MA). MI, Myocardial infarction; STS, Society of Thoracic Surgeons; MA, Massachusetts; Mass-DAC, Massachusetts Data Analysis Center.

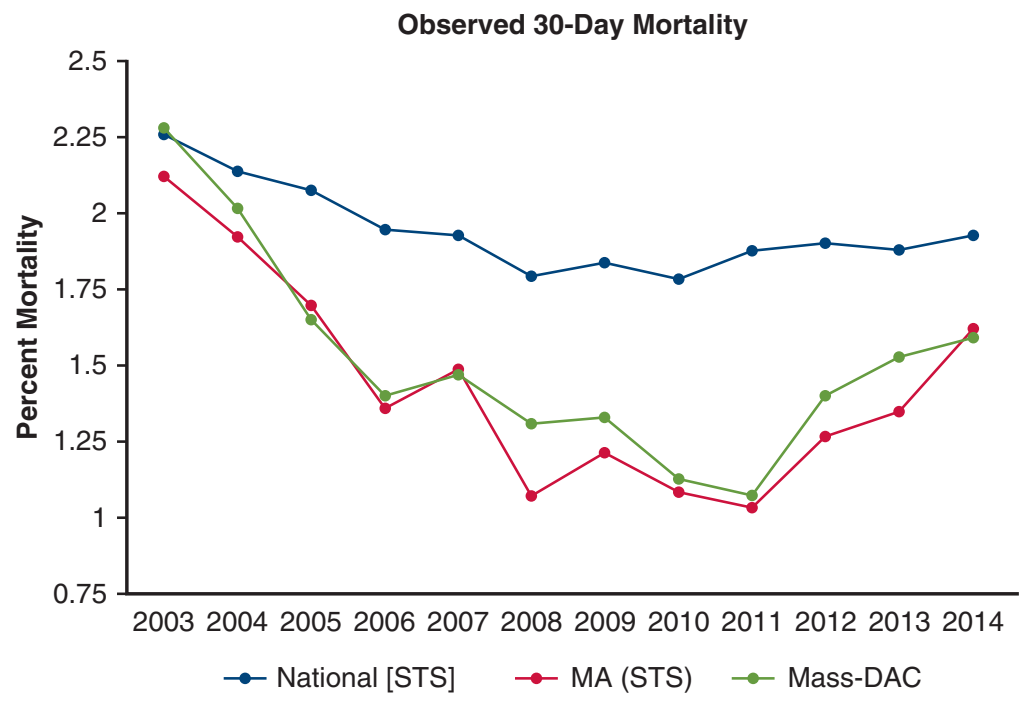

FIGURE E6. Massachusetts and national Society of Thoracic Surgeons (STS) 30-day observed mortality rates, 2003 to 2014. In 2003, observed 30-day mortality rates were similar for MA CABG patients (whether data were submitted directly to STS (MA [STS]) or analyzed by Mass-DAC) compared with national STS mortality rates (excluding MA). MA rates then decreased substantially and were consistently lower than national STS rates thereafter, although they increased after 2011. MA [STS], Massachusetts data submitted directly to STS; Mass-DAC, Massachusetts Data Analysis Center. 


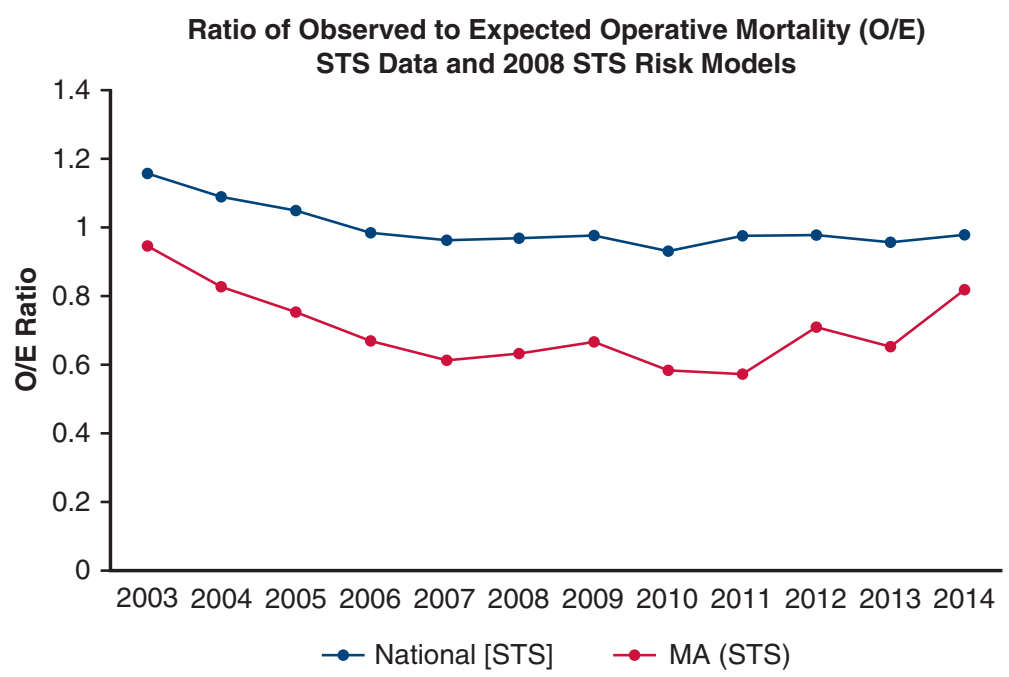

FIGURE E7. Ratios of observed to expected operative mortality for CABG, Massachusetts versus national STS results. For each public reporting year, using the same STS 2008 risk models, the ratios of observed to expected (O/E) operative mortality for MA patients in the STS Database were consistently less than one and also lower than national STS O/E ratios (excluding MA patients).

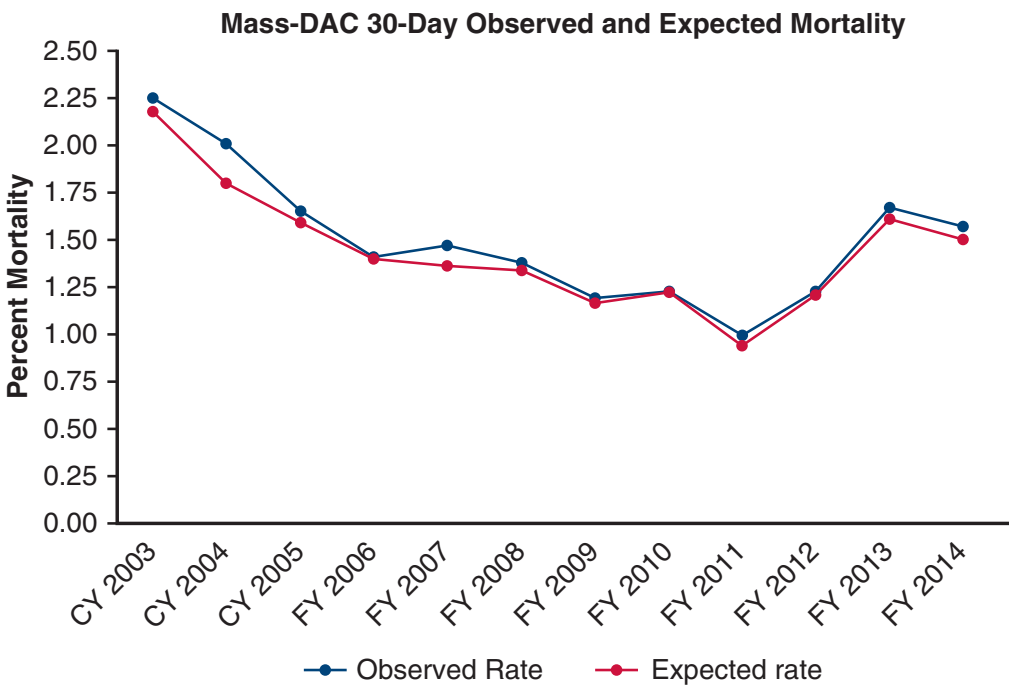

FIGURE E8. Massachusetts Data Analysis Center (Mass-DAC) 30-day observed and expected CABG mortality rates. Because Mass-DAC expected mortality rates were derived from risk models based only on the 14 MA programs and were re-estimated annually, observed and expected rates tracked closely.

\section{TABLE E1. Vital status ascertainment or verification}

External resources used include:

- Acute hospital case mix data from the Massachusetts Center for Health Information and Analysis Acute Hospital Case Mix Database (http://www. chiamass.gov/case-mix-data/).

- Vital statistics data from the Massachusetts Registry of Vital Records and Statistics (https://www.mass.gov/orgs/registry-of-vital-records-andstatistics) and, beginning in 2013, the Centers for Disease Control and Prevention National Death Index for out-of-state deaths (https://www.cdc. gov/nchs/ndi/).

- Massachusetts Data Analysis Center percutaneous coronary intervention registry data to validate prior percutaneous coronary intervention and other patient clinical data.

- Additional online resources such as the Social Security Death Index (http://www.deathindexes.com/ssdi.html), online obituaries, and the US Postal Service zip code lookup database (http://tools.usps.com/go/ZipLookupAction_input) were used as needed. 
TABLE E2. Isolated coronary artery bypass grafting (CABG) volumes: Society of Thoracic Surgeons (STS) national (without Massachusetts [MA]) per program and STS national (without MA) for 388 continuously participating STS programs, 2002 to 2014; New York decrease 2002 to 2014

\begin{tabular}{lcccc}
\hline & \multicolumn{2}{c}{ STS national data (overal)* } & \multicolumn{2}{c}{ STS national data (continuous participation) $\dagger$} \\
\cline { 2 - 4 } Year & No. of sites & Isolated CABG (n) & No. of sites & 124,037 \\
\hline 2002 & 495 & 151,799 & 388 & 116,379 \\
2003 & 539 & 150,801 & 388 & 105,409 \\
\hline 2004 & 607 & 147,884 & 388 & 94,890 \\
2005 & 704 & 150,616 & 388 & 89,513 \\
2006 & 787 & 158,046 & 388 & 84,549 \\
2007 & 859 & 161,167 & 388 & 80,115 \\
\hline 2008 & 933 & 165,055 & 388 & 75,593 \\
\hline 2009 & 965 & 164,228 & 388 & 71,251 \\
\hline 2010 & 996 & 157,838 & 388 & 64,189 \\
2011 & 1016 & 144,718 & 388 & 60,094 \\
\hline 2012 & 1026 & 138,408 & 388 & 60,146 \\
\hline 2013 & 1038 & 138,771 & 388 & 59,104 \\
\hline 2014 & 1041 & 137,702 & 388 & 59,369 \\
\hline 2015 & 1045 & 141,039 & 388 & 58,672 \\
\hline
\end{tabular}

Decrease per site STS overall $=(151,799 / 495-140,853 / 1046) / 306.7=56.1 \%$. Decrease at 388 sites with continuous STS participation 2002 to $2014=(124,037-58,672) /$ $124,037=52.7 \%$. CABG, Coronary artery bypass grafting. *Data from all sites contributing to STS Adult Cardiac Surgery Database other than Massachusetts (out of 1253 possible sites). $\dagger$ Data from 388 STS Adult Cardiac Surgery Database sites that reported cases for all years between 2002 and 2014.

New York CABG volumes

New York: 16,120 isolated CABG in 2002, 7942 in $2014=50.7 \%$ decrease. New York Data Sources from: 1. 2004 Adult cardiac surgery in New York State 2000-2002. Available at: https://www.health.ny.gov/statistics/diseases/cardiovascular/heart_disease/docs/2000-2002_adult_cardiac_surgery.pdf. Accessed September 29, 2017. 2. 2017 Adult cardiac surgery in New York State 2012-2014. Available at: https://www.health.ny.gov/statistics/diseases/cardiovascular/heart_disease/docs/2012-2014_adult_cardiac_surgery.pdf. Accessed September 29, 2017. 
TABLE E3. Major adjudication changes

\begin{tabular}{|c|c|c|c|c|c|c|c|c|c|c|c|}
\hline \multirow[b]{2}{*}{ Year } & \multirow[b]{2}{*}{ Total isolated CABG } & \multicolumn{4}{|c|}{ Cardiogenic shock } & \multicolumn{3}{|c|}{ Emergent or emergent-salvage } & \multicolumn{3}{|c|}{ MI $<\mathbf{2 4}$ h } \\
\hline & & Submitted & \multicolumn{2}{|c|}{$\%$ of CABG } & Changed & Submitted & $\%$ of CABG & Changed & Submitted & $\%$ of CABG & Changed \\
\hline 2007 & 3396 & 75 & & & $36(48.0)$ & 161 & 4.7 & $32(19.9)$ & 147 & 4.3 & $31(21.1)$ \\
\hline 2008 & 3336 & 85 & & & $32(37.6)$ & 159 & 4.8 & $27(17.0)$ & 139 & 4.2 & $22(15.8)$ \\
\hline 2009 & 3284 & 52 & & & $29(55.8)$ & 103 & 3.1 & $11(10.7)$ & 96 & 2.9 & $8(8.3)$ \\
\hline 2010 & 3169 & 36 & & & $21(58.3)$ & 87 & 2.7 & $10(11.5)$ & 86 & 2.7 & $7(8.1)$ \\
\hline 2011 & 2840 & 39 & & & $15(38.5)$ & 99 & 3.5 & $11(11.1)$ & 87 & 3.1 & $12(13.8)$ \\
\hline 2012 & 2680 & 29 & & & $7(24.1)$ & 93 & 3.5 & $8(8.6)$ & & & \\
\hline 2013 & 2941 & 35 & & & $6(17.1)$ & 93 & 3.2 & $14(15.1)$ & & & \\
\hline \multirow[t]{3}{*}{2014} & 3063 & 25 & & & $9(36.0)$ & 95 & 3.1 & $12(12.6)$ & & & \\
\hline & & \multicolumn{5}{|c|}{ Peripheral vascular disease } & \multicolumn{5}{|c|}{ Isolated CABG } \\
\hline & Total isolated CABG & \multicolumn{2}{|c|}{ Submitted } & \multicolumn{2}{|c|}{$\%$ of CABG } & Changed & $\begin{array}{r}\text { Sub } \\
\text { CAB }\end{array}$ & $\begin{array}{l}\text { mitted as } \\
G+\text { Other }\end{array}$ & \multicolumn{3}{|c|}{ Changed to isolated CABG } \\
\hline 2007 & 3396 & & & & & & & 149 & & $93(62.4$ & \\
\hline 2008 & 3336 & & & & & & & 136 & & $89(65.4$ & \\
\hline 2009 & 3284 & & & & & & & 143 & & $88(61.5$ & \\
\hline 2010 & 3169 & & & & & & & 174 & & $62(35.6$ & \\
\hline 2011 & 2840 & & & & & & & 133 & & $44(33.1$ & \\
\hline 2012 & 2680 & 41 & & & 15.4 & $71(17.2)$ & & 75 & & $31(41.3$ & \\
\hline 2013 & 2941 & 40 & & & 13.9 & $36(8.8)$ & & 70 & & $39(55.7$ & \\
\hline 2014 & 3063 & 43 & & & 14.3 & $68(15.5)$ & & 98 & & $55(56.1$ & \\
\hline
\end{tabular}

Values are presented as $\mathrm{n}$, or $\%$, or $\mathrm{n}(\%) . M I$, Myocardial infarction; $C A B G$, coronary artery bypass grafting. 
TABLE E4. Risk factor odds ratios and relative change in odds, Massachusetts (MA) relative to national

\begin{tabular}{|c|c|c|}
\hline Risk factor & Model parameter & Odds ratio $(99 \%$ confidence interval) \\
\hline Diabetes & Year & $1.0452(1.044-1.0464)$ \\
\hline Insulin & Year & $1.0577(1.056-1.0595)$ \\
\hline Moderate/severe chronic lung disease & Year & $1.0173(1.0154-1.0193)$ \\
\hline Morbid obese & Year & $1.0244(1.0228-1.026)$ \\
\hline Cardiogenic shock & Year & $1.0012(0.9971-1.0053)$ \\
\hline Peripheral vascular disease & Year & $0.9899(0.9883-0.9914)$ \\
\hline Cerebrovascular disease & Year & $1.0123(1.0107-1.0139)$ \\
\hline Reoperation & Year & $0.9459(0.9425-0.9493)$ \\
\hline Emergent/salvage & Year & $0.9993(0.9967-1.0019)$ \\
\hline Ejection fraction $<30 \%$ & Year & $0.9982(0.9958-1.0006)$ \\
\hline Ejection fraction $30 \%-39 \%$ & Year & $0.9854(0.9835-0.9873)$ \\
\hline Preoperative dialysis & Year & $1.0681(1.0641-1.0722)$ \\
\hline Age $65-74$ y & Year & $1.0142(1.013-1.0154)$ \\
\hline Age $\geq 75$ y & Year & $0.9806(0.9792-0.982)$ \\
\hline Female & Year & $0.9884(0.9871-0.9896)$ \\
\hline Diabetes & MA & $1.1163(1.0653-1.1696)$ \\
\hline Insulin & MA & $1.041(1.0023-1.0813)$ \\
\hline Moderate/severe chronic lung disease & MA & $0.6302(0.5719-0.6944)$ \\
\hline Morbid obese & MA & $0.8608(0.8294-0.8934)$ \\
\hline Cardiogenic shock & MA & $0.6637(0.5322-0.8277)$ \\
\hline Peripheral vascular disease & MA & $1.2153(1.1438-1.2913)$ \\
\hline Cerebrovascular disease & MA & $1.0159(0.9791-1.0541)$ \\
\hline Reoperation & MA & $0.5062(0.4586-0.5588)$ \\
\hline Emergent/Salvage & MA & $0.5665(0.5237-0.6129)$ \\
\hline Ejection fraction $<30 \%$ & MA & $1.2662(1.1598-1.3823)$ \\
\hline Ejection fraction $30 \%-39 \%$ & MA & $1.1241(1.045-1.2093)$ \\
\hline Preoperative dialysis & MA & $0.8188(0.7435-0.9018)$ \\
\hline Age $65-74$ y & MA & $1.0062(0.9788-1.0343)$ \\
\hline Age $\geq 75$ y & MA & $1.2786(1.2409-1.3175)$ \\
\hline Female & MA & $0.8768(0.8316-0.9244)$ \\
\hline Diabetes & MA $\times$ Year & $0.9789(0.9716-0.9864)$ \\
\hline Insulin & MA $\times$ Year & $1(1-1)$ \\
\hline Moderate/severe chronic lung disease & MA $\times$ Year & $0.9708(0.9553-0.9866)$ \\
\hline Morbid obese & MA $\times$ Year & $1(1-1)$ \\
\hline Cardiogenic shock & MA $\times$ Year & $0.9053(0.8671-0.9451)$ \\
\hline Peripheral vascular disease & MA $\times$ Year & $0.9704(0.9605-0.9805)$ \\
\hline Cerebrovascular disease & MA $\times$ Year & $1(1-1)$ \\
\hline Reoperation & MA $\times$ Year & $1(1-1)$ \\
\hline Emergent/salvage & MA $\times$ Year & $1(1-1)$ \\
\hline Ejection fraction $<30 \%$ & MA $\times$ Year & $0.9648(0.9504-0.9795)$ \\
\hline Ejection fraction $30 \%-39 \%$ & MA $\times$ Year & $0.9817(0.9695-0.994)$ \\
\hline Preoperative dialysis & MA $\times$ Year & $1(1-1)$ \\
\hline Age $65-74$ y & MA $\times$ Year & $1(1-1)$ \\
\hline Age $\geq 75$ y & MA $\times$ Year & $1(1-1)$ \\
\hline Female & MA $\times$ Year & $0.9913(0.9826-1)$ \\
\hline
\end{tabular}

MA, Massachusetts. 